WSRC-TR-2001-00391

KEYWORDS:

Sludge Suspension

Computational Approach

CFD Approach

Jet Flow Model

Mixing Pump Model

RETENTION - Permanent

\title{
PERFORMANCE ANALYSIS FOR MIXING PUMPS IN TANK 18
}

SAVANNAH RIVER TECHNOLOGY CENTER

Si Young Lee and Richard A. Dimenna

October 2001

Westinghouse Savannah River Company

Savannah River Site

Aiken, SC 29808

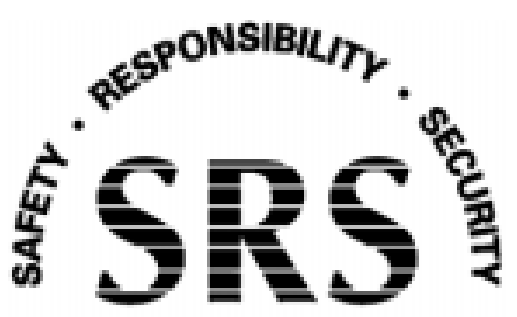

SAVANNAH RIVER SITE

Prepared for the U.S. Department of Energy under Contract No. DE-AC09-96SR18500 
This document was prepared in conjunction with work accomplished under Contract No. DEAC09-96SR18500 with the U.S. Department of Energy.

\section{DISCLAIMER}

This report was prepared as an account of work sponsored by an agency of the United States Government. Neither the United States Government nor any agency thereof, nor any of their employees, makes any warranty, express or implied, or assumes any legal liability or responsibility for the accuracy, completeness, or usefulness of any information, apparatus, product or process disclosed, or represents that its use would not infringe privately owned rights. Reference herein to any specific commercial product, process or service by trade name, trademark, manufacturer, or otherwise does not necessarily constitute or imply its endorsement, recommendation, or favoring by the United States Government or any agency thereof. The views and opinions of authors expressed herein do not necessarily state or reflect those of the United States Government or any agency thereof.

This report has been reproduced directly from the best available copy.

Available for sale to the public, in paper, from: U.S. Department of Commerce, National Technical Information Service, 5285 Port Royal Road, Springfield, VA 22161

phone: (800) 553-6847

fax: (703) 605-6900

email: orders@ntis.fedworld.gov

online ordering: http://www.ntis.gov/support/index.html

Available electronically at http://www.osti.gov/bridge

Available for a processing fee to U.S. Department of Energy and its contractors, in paper, from: U.S. Department of Energy, Office of Scientific and Technical Information, P.O. Box 62, Oak Ridge, TN 37831-0062

phone: (865)576-8401

fax: (865)576-5728

email: reports@adonis.osti.gov 
DOCUMENT: $\quad$ WSRC-TR-2001-00391

TITLE: $\quad$ Performance Analysis for Mixing Pumps in Tank 18

\section{APPROVALS}

Si Y. Lee, Author (EM\&S Group/ SRTC)

Date:

Date:

Richard A. Dimenna, Co-Author (EM\&S Group/ SRTC)

Robert A. Leishear, Technical Reviewer (WRC Engineering)

Cynthia P. Holding-Smith, Manager (EM\&S Group/SRTC)

Date:

Date:

Steve T. Wach, Manager (EDS/SRTC)

Date: 
(This Page Intentionally Left Blank)

-iv- 


\section{Table of Contents}

List of Figures vii

List of Tables $\quad$ x

Nomenclature $\quad$ xi

$\begin{array}{ll}\text { Abstract } & 1\end{array}$

1 Introduction 2

2. Modeling Approach and Analysis 3

2. 1 TNX Tank Model................................................................................... 9

2.2 Tank 18 Simulation Models with ADMP and MADMP Mixers ............................. 12

3. Results and Discussions 15

4. Summary and Conclusions $\quad 54$

$\begin{array}{ll}\text { 5. References } & 57\end{array}$

Appendix A: Mapping of Velocity Measurement Sensor and Benchmarking Results

Appendix B: Quantitative Estimation of the Remaining Sludge and Zeolite Volume 
(This Page Intentionally Left Blank) 


\section{List of Figures}

Figure 1. Flow developments and evolutions of a jet flow along the discharge direction .... 7

Figure 2. Three-dimensional modeling boundary for the benchmarking analysis of the full tank test facility with ADMP mixer pump at TNX

Figure 3. Three-dimensional modeling boundary for the transient flow pattern analysis of the full tank test facility with ADMP mixer pump considering pump rotational effect.....

Figure 4. Schematic illustrations and modeling boundary of Tank18 with ADMP mixer

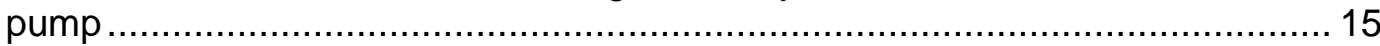

Figure 5. Non-uniform mesh nodes for the TNX tank model on x-y computational domain near the pump nozzle (Total number of computational mesh nodes for the model is 731,087 .)

Figure 6. Non-uniform mesh nodes for the Tank 18 simulation model (Case-I) on $x-y$ computational domain (Total number of mesh nodes is 256,360.)

Figure 7. Quantitative comparison of flow patterns generated by the ADMP mixer of the TNX tank between the 2-D and 3-D CFD model results at the pump discharge plane.

Figure 7a. Quantitative comparison of flow evolutions generated by the ADMP mixer of the TNX tank between the 2-D and 3-D CFD model results along the discharge direction of a nozzle.

Figure 7b. Quantitative comparison of vorticity and turbulence dissipation rate generated by the ADMP mixer of the TNX tank between the 2-D and 3-D CFD model results along the discharge direction of a nozzle.

Figure 7c. Qualitative comparison of flow patterns generated by the ADMP mixer of the TNX tank between the 2-D and 3-D CFD model results at the pump discharge plane (The shaded area has the velocity lower than the one required for resuspension or mixing of sludge.)

Figure 8. Flow patterns at two different transient times on the discharge plane of the TNX full tank facility for the initially quiescent tank

Figure 9. Comparison of the model predictions with the TNX test data for 3-inch elevation and 27 -inch plane for near the discharge direction.

Figure 10a. Comparison of the model predictions with the TNX test data along the distance from the nozzle inlet on the centerline of pump discharge (the model predictions are represented by the test data within $\pm 25 \%$.)

Figure 10b. Comparison of the model predictions with the peak and arithmetic averages of the TNX data along the distance from the nozzle inlet near the centerline of pump discharge.

Figure 11. Comparison of the TNX model predictions of the discharge velocities with the test data near the centerline of the pump discharge direction at the plane 3in above the tank bottom.

Figure 12. Comparison of the TNX model predictions with all the TNX test data 29

Figure 13. Benchmarking results of the full TNX tank model against the SRS test data and literature data

Figure 14. Comparison of the flow evolutions from the nozzle exit to the tank wall between the two cases (tank mixing with and without pump rotation) at various elevations above the tank bottom 
Figure 15. Transient evolution results of the TNX full tank model with $0.25 \mathrm{rpm}$ pump rotation at the discharge plane 27 in above the tank bottom ....

Figure 16. Transient flow evolutions along the discharge direction of Tank 18 at the elevation of pump nozzle center (27in above the tank bottom) ....

Figure 17. Transient flow evolutions along the downstream direction of Tank 18 at the 3in elevation of pump nozzle center...

Figure 18. Steady-state horizontal velocity profiles for various distances from the pump at the nozzle discharge plane (27 inches above tank bottom): 3D Model Results for the Full Tank 18 Facility with 70" liquid level

Figure 19. Steady-state vertical velocity profiles for various distances from the pump (pump nozzle is located 2.25ft from tank bottom): 3D Model Results for the Full Tank 18 Facility with 70" liquid level

Figure 20. Downstream evolutions of Tank 18 with and without pump rotations for 70in tank level at the discharge plane 27 inches above the tank bottom.

Figure 21. Downstream evolutions of Tank 18 with and without pump rotations for 70in tank level at the plane 3 inches above the tank bottom.

Figure 22. Comparison of steady-state velocity profiles near the wall regions about $12 \mathrm{ft}$ and $2 \mathrm{ft}$ away from the side wall of Tank 18 at the plane 3in above tank bottom.

Figure 23. Comparison of steady-state flow patterns of the 3in plane for Tank 18 without pump rotation and with pump rotation (The red zone is higher than $1.6 \mathrm{ft} / \mathrm{sec}$ of flow velocty.)

Figure 24. Comparison of steady-state velocity contour plots for Tank 18 without pump rotation and with pump rotation at the plane 3in above the tank bottom (The zone inside the red curve is higher than $1.6 \mathrm{ft} / \mathrm{sec}$ of flow velocity.)

Figure 25 . Velocity profiles for various distances from the pump at the nozzle discharge plane (27 inches above tank bottom)

Figure 26. Velocity profiles for various distances from the pump at the nozzle discharge plane (3 inches above tank bottom)

Figure 27. Vertical velocity profiles of two different tank levels for various distances from the pump (pump nozzle is located $2.25 \mathrm{ft}$ from tank bottom).

Figure 28. Downstream evolutions of Tank 18 with and without pump rotations for 40in tank level at the discharge plane 27 inches above the tank bottom.

Figure 29. Downstream evolutions of Tank 18 with and without pump rotations for 40in tank level at the discharge plane 3 inches above the tank bottom.

Figure 30. Steady-state downstream evolutions of Tank 18 with and without pump rotations for 40in tank level at the discharge plane 27 inches above the tank bottom.

Figure 31. Steady-state downstream evolutions of Tank 18 with and without pump rotations for 40in tank level at the discharge plane 3 inches above the tank bottom.

Figure 32. Downstream velocity profiles along the discharge directions of the nozzle planes of Tank 19 ADMP and MADMP mixers (The mapping name Tank 18 in the figure means Tank 18 operation with the existing ADMP.)

Figure 33. Horizontal velocity profiles along the downstream directions of the pump nozzles of Tank 18 with ADMP and MADMP mixers at the plane 3 in above the tank bottom.

Figure 34. Comparison of turbulence intensity profiles for the Tank 18 operations with ADMP and MADMP mixers at the plane 3in above the tank bottom

Figure 35. Comparisons of turbulence intensity profiles for the Tank 18 operations with ADMP and MADMP mixers at the plane 3in above the tank bottom (The 
mapping name Tank 18 in the figure means Tank 18 operation with the existing ADMP.)

Figure 36. Nondimensional velocity distributions along the discharge direction of pump nozzle at the nozzle plane 27in above the tank bottom (The mapping name Tank 18 in the figure means Tank 18 operation with the existing ADMP.)....

Figure 37. Nondimensional velocity distributions along the discharge direction of pump nozzle at the plane 3in above the tank bottom (The mapping name Tank 18 in the figure means Tank 18 operation with the existing ADMP.)...

Figure 38. Comparison of flow evolutions induced by the Tank 18 ADMP and MADMP mixers with 70in tank levels on the discharge plane 27in above the tank bottom

Figure 39. Comparison of flow evolutions induced by the Tank 18 ADMP and MADMP mixers with 70in tank levels on the horizontal plane 3in above the tank bottom

Figure 40. Comparison of flow evolutions induced by the Tank 18 ADMP and MADMP mixers at the top surfaces of 70in tank levels

Figure 41. Comparison of velocity contour plots induced by the Tank 18 ADMP and MADMP mixers at the center planes of 70in tank levels

Figure 42. Comparison of suspended zones of zeolites induced by the Tank 18 ADMP and MADMP mixers at the center planes of 70in tank levels

Figure 43. Comparison of flow patterns induced by the Tank 18 ADMP and MADMP mixers at the center planes of 70in tank levels

Figure 44. Comparison of flow evolutions with two different mixing fluids induced by the Tank 18 ADMP mixer at the 27in (nozzle exit level) and 3in elevations from the tank bottom

Figure 45. Comparison of flow evolutions with water and slurry fluids induced by the Tank 18 ADMP mixer at the 3in elevations from the tank bottom .

Figure 46. Comparisons of steady-state non-dimensional velocity profiles of Tank 18 at the discharge plane of ADMP mixer 27in above tank bottom with literature data

Figure 47. Typical velocity profiles in the direction perpendicular to the free surface from the modeling results of Tank 18 mixing simulations.

Figure 48. Typical velocity profiles in the direction parallel to the free surface from the modeling results of Tank 18 mixing simulations.

Figure A.1. Mapping of velocity measurement sensor and notations of test number I.D.

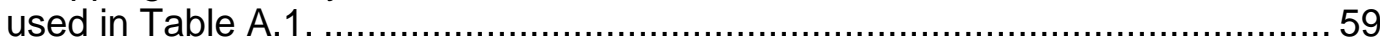

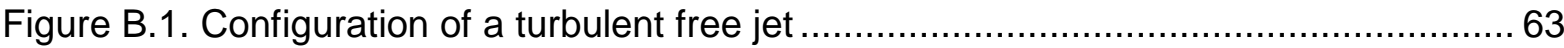

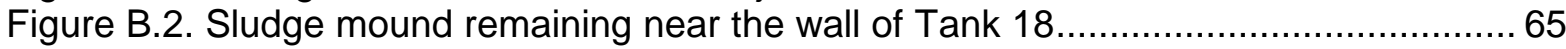

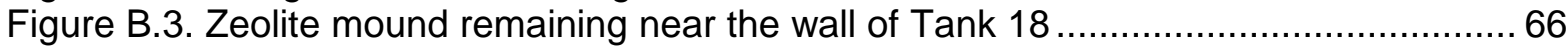




\section{List of Tables}

Table 1. Specifications of slurry pumps used for the present analysis.

Table 2. Minimum velocities of particle pickup and removal for the various particle sizes

(fluid density=1.5SG, particle density=2.0SG, sludge thickness=3in, solid concentration $=0.1$ ).

Table 3. CFD modeling approaches taken for the present analysis................................. 8

Table 4. Reference design and operating conditions used for the present analysis. ..........10

Table 5. Detailed analysis cases and conditions for the three-dimensional Tank 18 model....

Table 6. Comparison of operational times to reach steady-state mixing flow patterns for two different situations with and without pump rotations

Table 7. Sensitivity results for different fluid properties in the Tank 18 model in terms of maximum clearing distance (MCD)

Table 8. Summary for the TNX model and Tank 18 model results of maximum clearing distance (MCD) for the cases considered in the analysis (Each case is defined in Table 2.).

Table A.1. Benchmarking results for TNX test with 3" and 27" elevations from the tank bottom 


\section{Nomenclature}

$\mathrm{A}=$ area $\left(\mathrm{ft}^{2}\right.$ or $\left.\mathrm{m}^{2}\right)$

$\mathrm{d}=$ nozzle diameter (ft or $\mathrm{m}$ )

$\mathrm{D}=$ tank diameter (ft or $\mathrm{m}$ )

$\mathrm{C}=$ constant or interpolation factor (--)

$\mathrm{F}=$ Force $(\mathrm{N})$

$\mathrm{g}=$ gravity $\left(\mathrm{m} / \mathrm{sec}^{2}\right)$

$\mathrm{h}=$ liquid height above the nozzle (inch)

$\mathrm{H}=$ total tank level (inch)

$\mathrm{I}=$ turbulence intensity (--)

$\mathrm{k}=$ turbulent kinetic energy $\left(=\frac{1}{2}\left(u^{\prime 2}+v^{\prime 2}+w^{\prime 2}\right)_{\text {avg }}\right)$

$\mathrm{P}=$ pressure $(\mathrm{Pa})$

$\operatorname{Pr}=$ Prandtl number, $\mu \mathrm{C}_{\mathrm{p}} / \mathrm{k},(--)$

$r=$ radial distance from the center of tank center ( $\mathrm{ft}$ or $\mathrm{m}$ )

$\mathrm{R}=$ tank radius ( $\mathrm{ft}$ or $\mathrm{m}$ )

$R e=$ Reynolds number, $d \rho u / \mu$

$\mathrm{t}=$ time (second)

$\mathrm{U}=$ nozzle exit velocity $(\mathrm{ft} / \mathrm{sec}$ or $\mathrm{m} / \mathrm{sec}$ )

$\mathrm{u}=$ component velocity in $\mathrm{x}$-direction (ft/sec or $\mathrm{m} / \mathrm{sec}$ )

$u^{\prime}=$ local turbulent velocity fluctuation in $\mathrm{x}$-direction ( $\mathrm{ft} / \mathrm{sec}$ or $\mathrm{m} / \mathrm{sec}$ )

$\mathrm{v}=$ local flow velocity or component velocity in $\mathrm{y}$-direction (ft/sec or $\mathrm{m} / \mathrm{sec}$ )

$v^{\prime}=$ local turbulent velocity fluctuation in y-direction (ft/sec or $\mathrm{m} / \mathrm{sec}$ )

$\mathrm{V}=$ average velocity magnitude ( $\mathrm{ft} / \mathrm{sec}$ or $\mathrm{m} / \mathrm{sec}$ )

$\mathrm{w}=$ component velocity in $\mathrm{z}$-direction $(\mathrm{ft} / \mathrm{sec}$ or $\mathrm{m} / \mathrm{sec}$ )

$\mathrm{w}^{\prime}=$ local turbulent velocity fluctuation in z-direction ( $\mathrm{ft} / \mathrm{sec}$ or $\mathrm{m} / \mathrm{sec}$ )

$\mathrm{x}=$ local position along the $\mathrm{x}$-direction under Cartesian coordinate system (ft or $\mathrm{m}$ )

$y=$ local position along the $y$-direction under Cartesian coordinate system (ft or $\mathrm{m}$ )

$\mathrm{z}=$ local position along the $\mathrm{y}$-direction under Cartesian coordinate system (ft or $\mathrm{m}$ )

\section{Greek}

$\rho=$ density $\left(\mathrm{kg} / \mathrm{m}^{3}\right)$

$\varepsilon=$ rate of dissipation of turbulent kinetic energy 


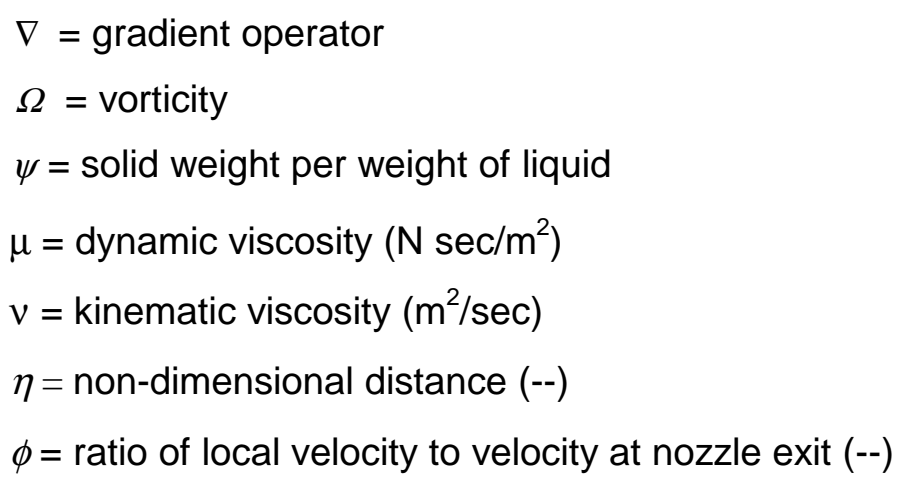

\section{Subscript}

$$
\begin{aligned}
& \text { avg = average } \\
& f=\text { fluid } \\
& f o=\text { clear fluid } \\
& f s=\text { suspended fluid } \\
& L=\text { lifting } \\
& m=\text { maximum } \\
& o=\text { jet nozzle exit } \\
& p=\text { particle or pump } \\
& s=\text { static } \\
& t=\text { turbulent flow } \\
& v=\text { flow velocity or vertical } \\
& \mu=\text { viscosity }
\end{aligned}
$$




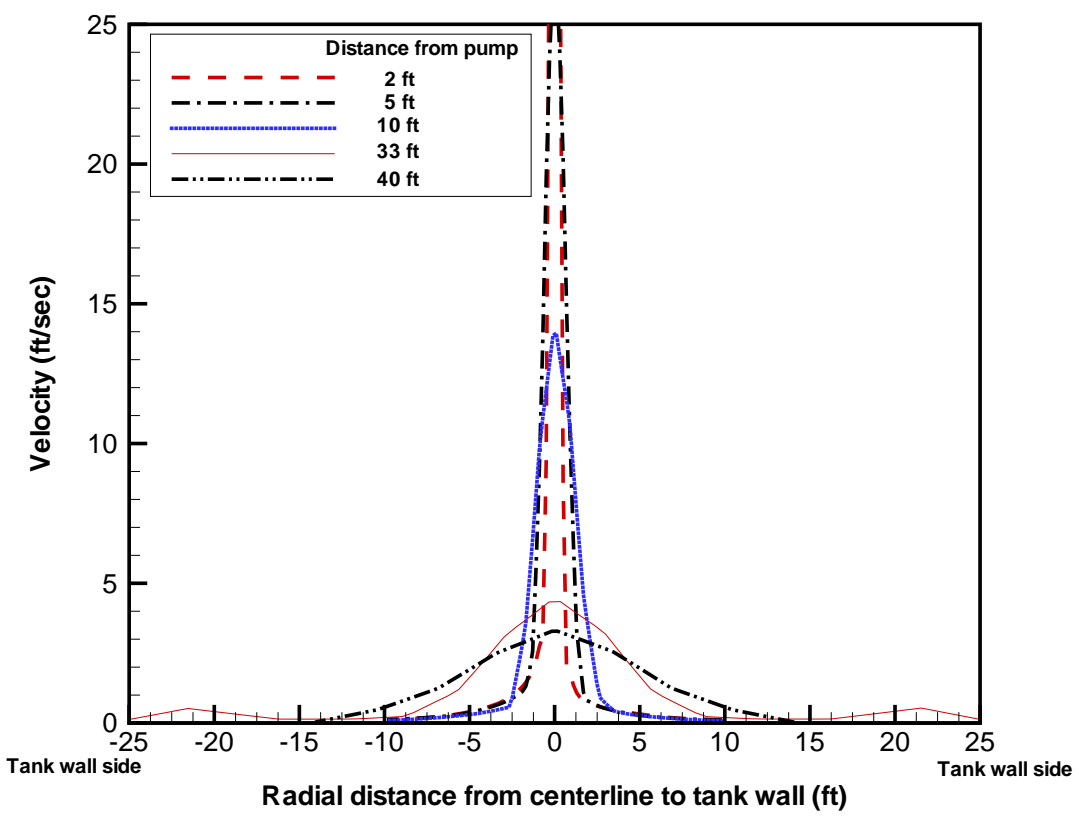

Figure 18. Steady-state horizontal velocity profiles for various distances from the pump at the nozzle discharge plane (27 inches above tank bottom): 3D Model Results for the Full Tank 18 Facility with 70" liquid level

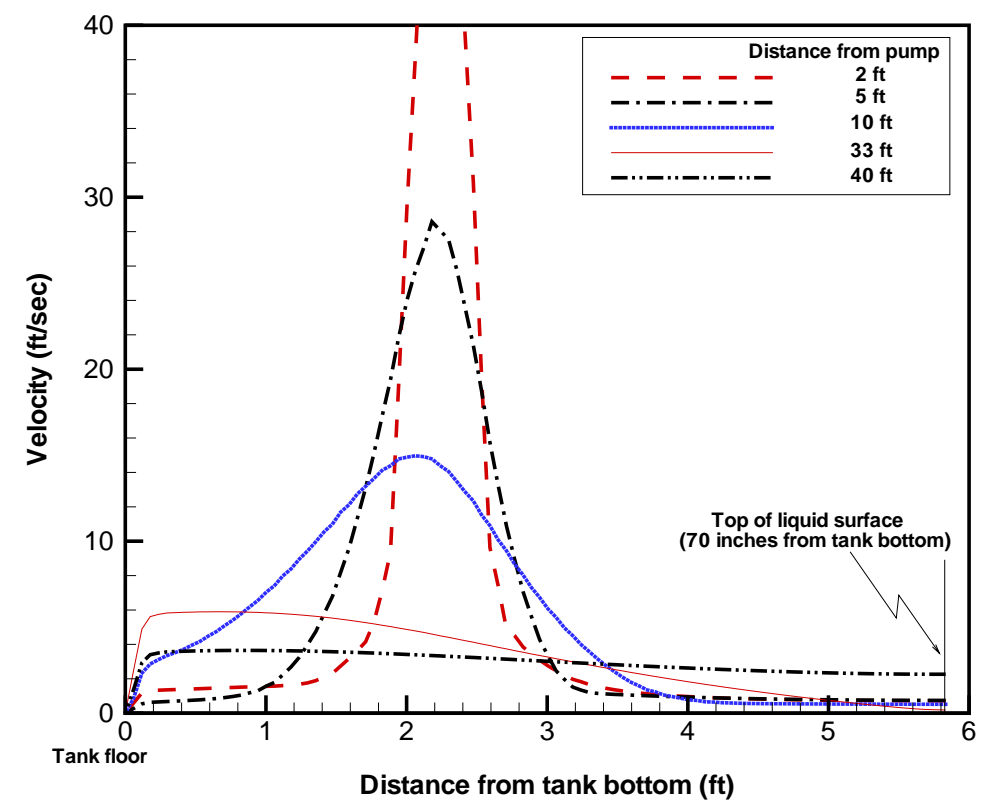

Figure 19. Steady-state vertical velocity profiles for various distances from the pump (pump nozzle is located 2.25ft from tank bottom): 3D Model Results for the Full Tank 18 Facility with 70" liquid level 


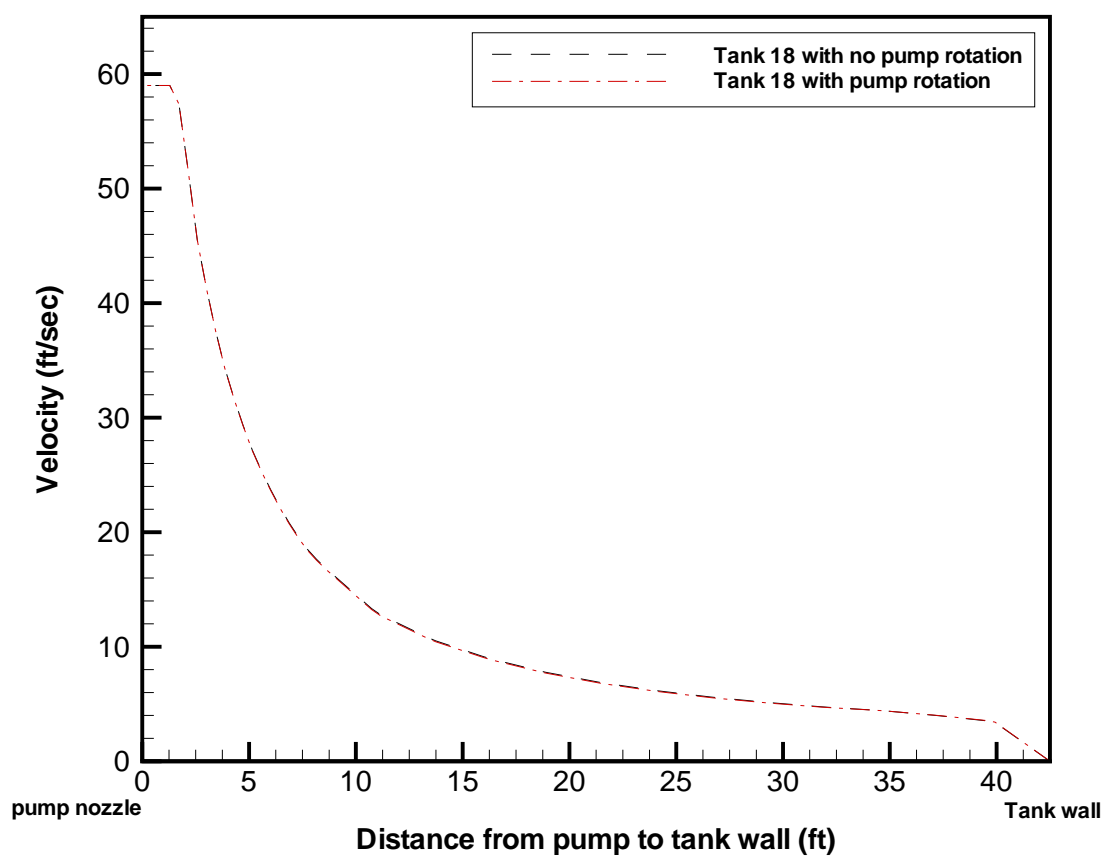

Figure 20. Downstream evolutions of Tank 18 with and without pump rotations for 70 in tank level at the discharge plane 27 inches above the tank bottom.

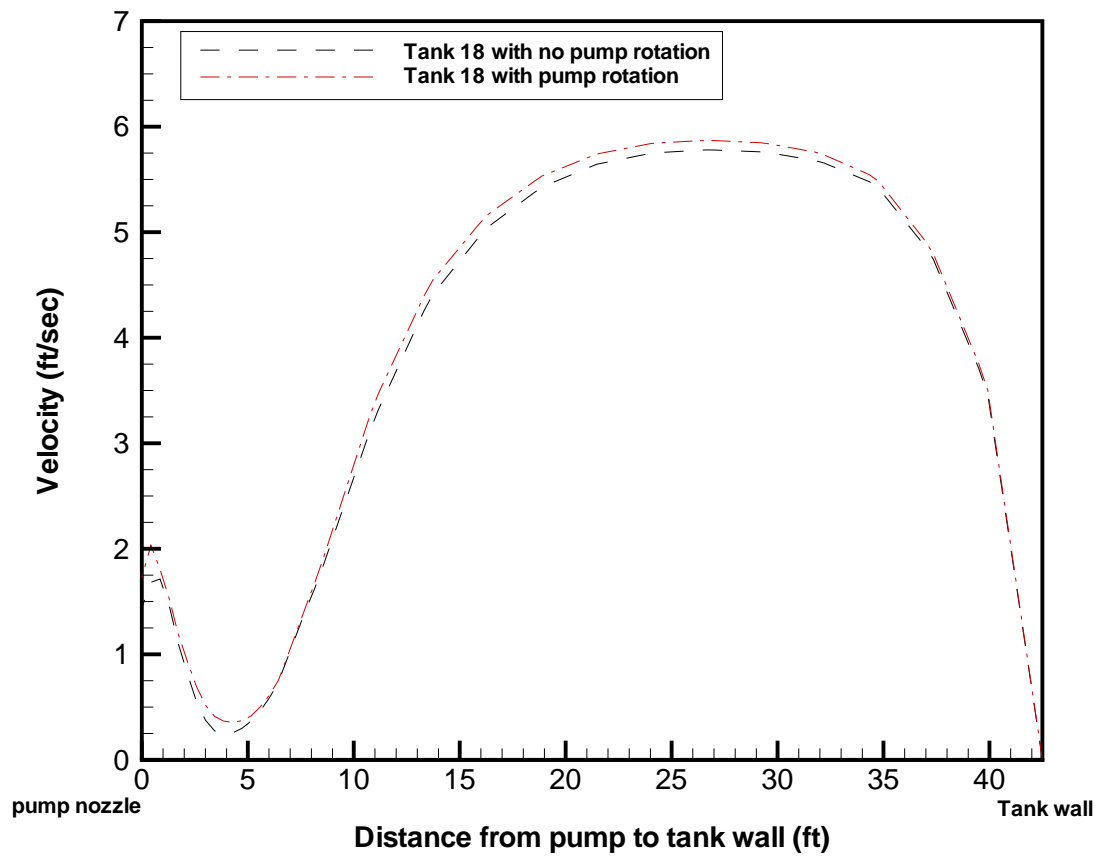

Figure 21. Downstream evolutions of Tank 18 with and without pump rotations for 70 in tank level at the plane 3 inches above the tank bottom. 

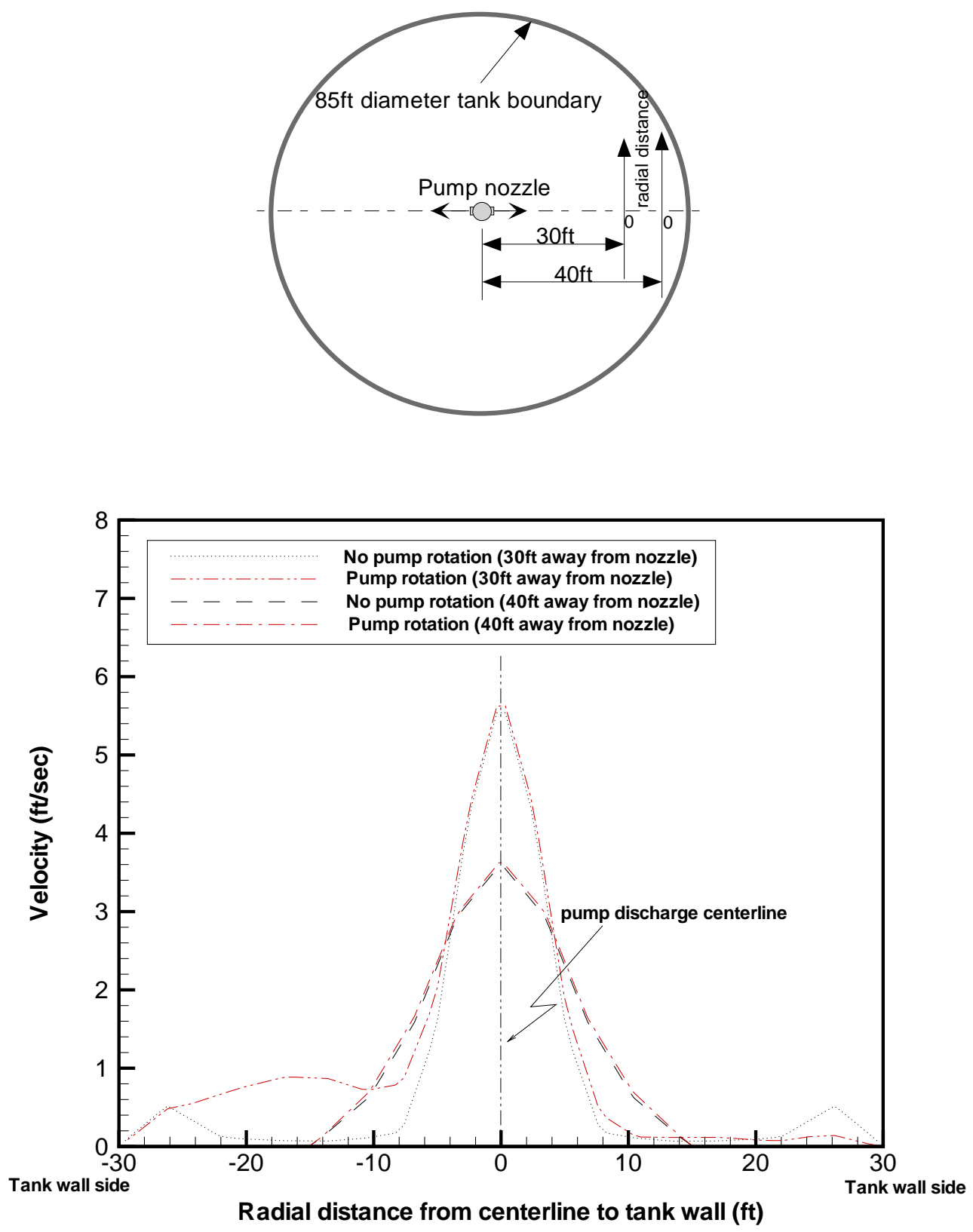

Figure 22. Comparison of steady-state velocity profiles near the wall regions about $12 \mathrm{ft}$ and $2 \mathrm{ft}$ away from the side wall of Tank 18 at the plane 3 in above tank bottom 
Report: WSRC-TR-2001-00391

Date: $\quad 04 / 05 / 02$

Page: $\quad 38$ of 66
WESTINGHOUSE SAVANNAH RIVER COMPANY

PERFORMANCE ANALYSIS FOR MIXING PUMPS OF TANK 18
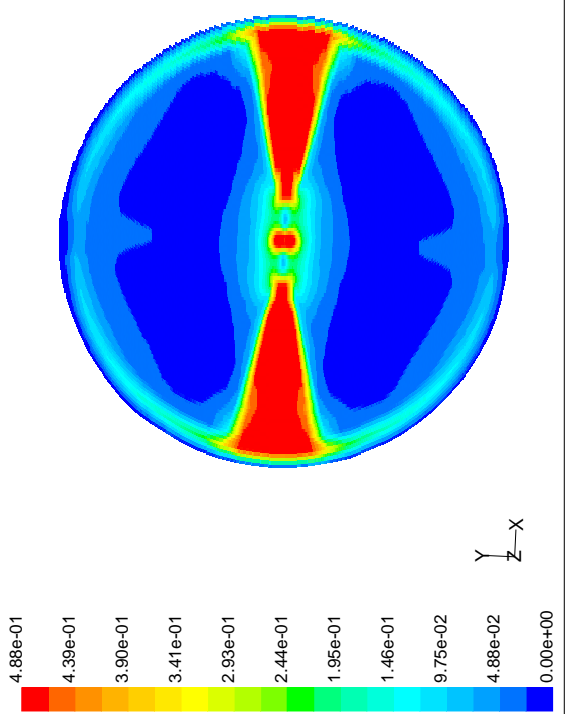

(Flow patterns for no pump rotation)

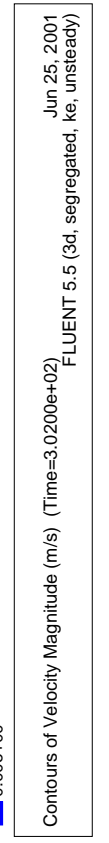

$\dot{d}$
$\dot{\omega}$
$\dot{\varpi}$
$\dot{\sim}$

Figure 23. Comparison of steady-state flow patterns of the 3 in plane for Tank 18 without pump rotation and with pump rotation (The red zone is higher than $1.6 \mathrm{ft} / \mathrm{sec}$ of flow velocty.)
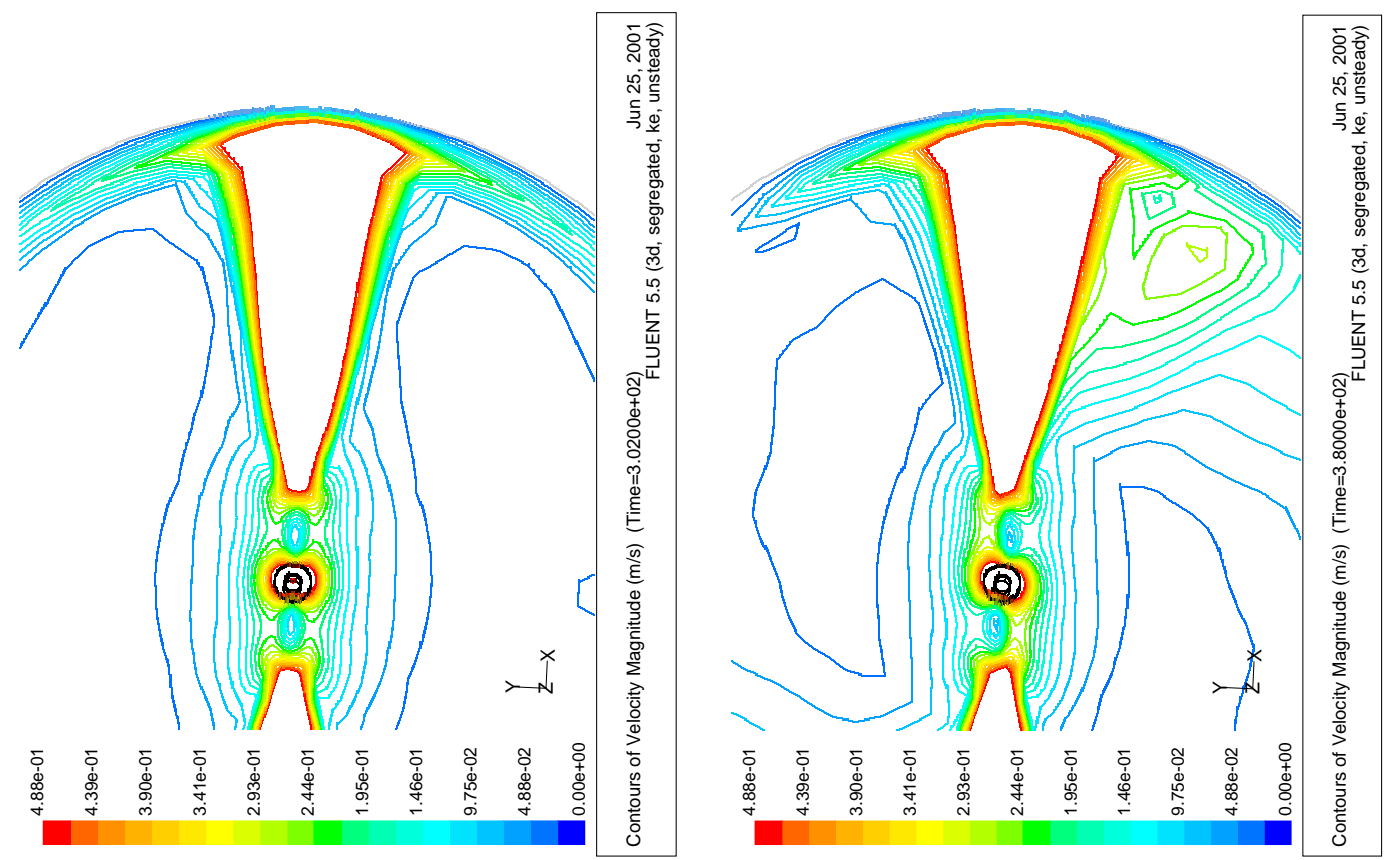

(Near-wall flow pattern for no pump rotation)

(Near-wall flow pattern for pump rotation)

Figure 24. Comparison of steady-state velocity contour plots for Tank 18 without pump rotation and with pump rotation at the plane 3 in above the tank bottom (The zone inside the red curve is higher than $1.6 \mathrm{ft} / \mathrm{sec}$ of flow velocity.) 


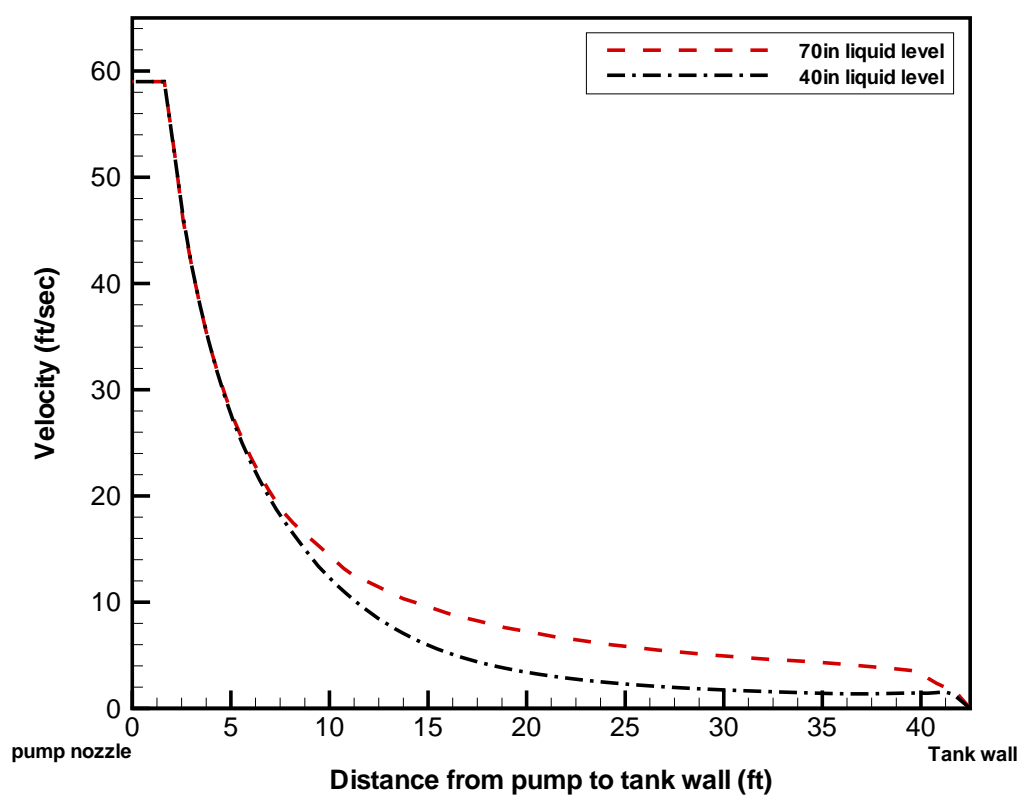

Figure 25. Velocity profiles for various distances from the pump at the nozzle discharge plane (27 inches above tank bottom)

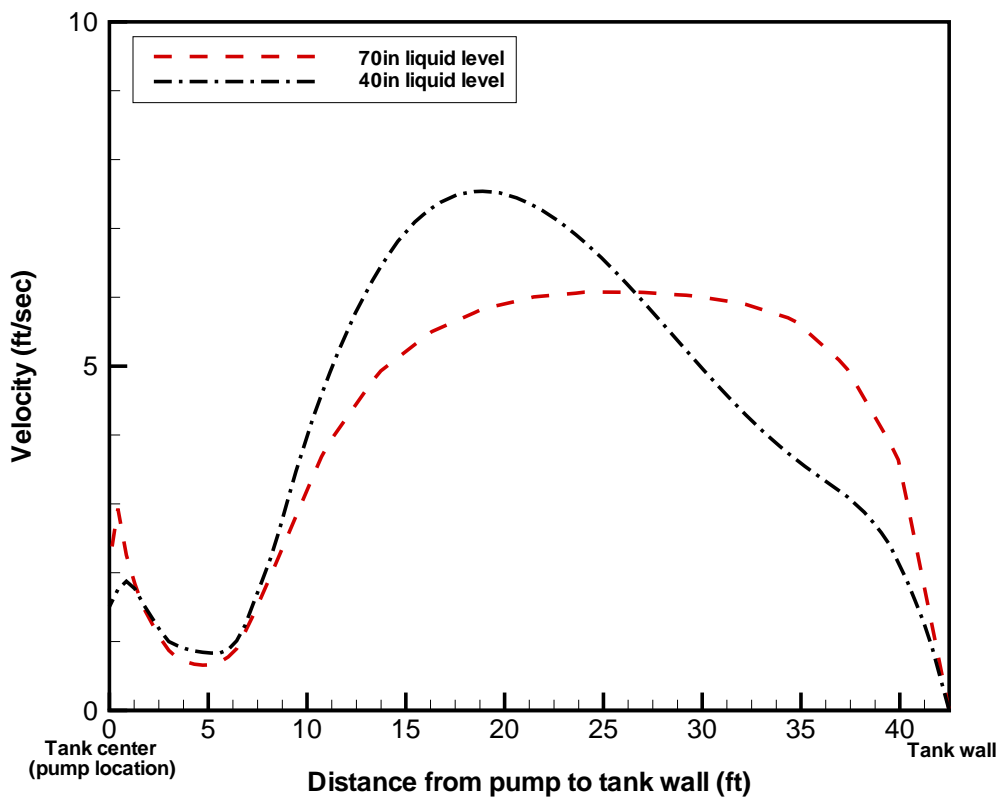

Figure 26. Velocity profiles for various distances from the pump at the nozzle discharge plane (3 inches above tank bottom) 
Report: WSRC-TR-2001-00391

Date: $\quad 04 / 05 / 02$

Page: $\quad 40$ of 66
WESTINGHOUSE SAVANNAH RIVER COMPANY

PERFORMANCE ANALYSIS FOR MIXING PUMPS OF TANK 18

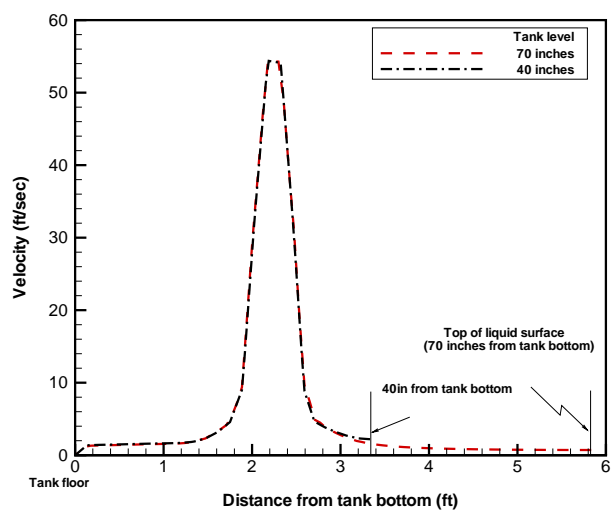

( $2 \mathrm{ft}$ from the pump)

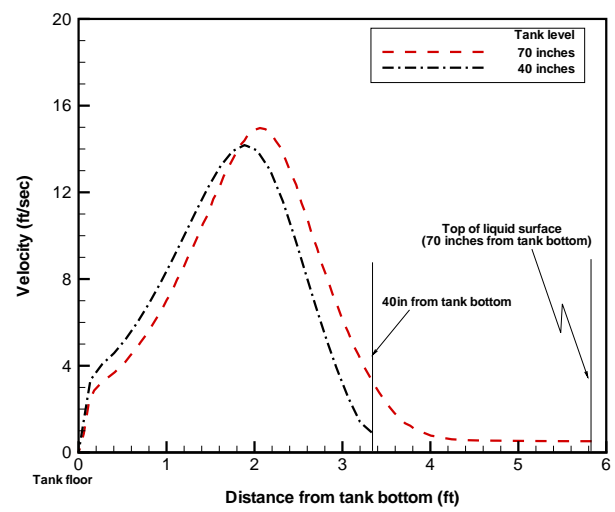

(10 $\mathrm{ft}$ from the pump)

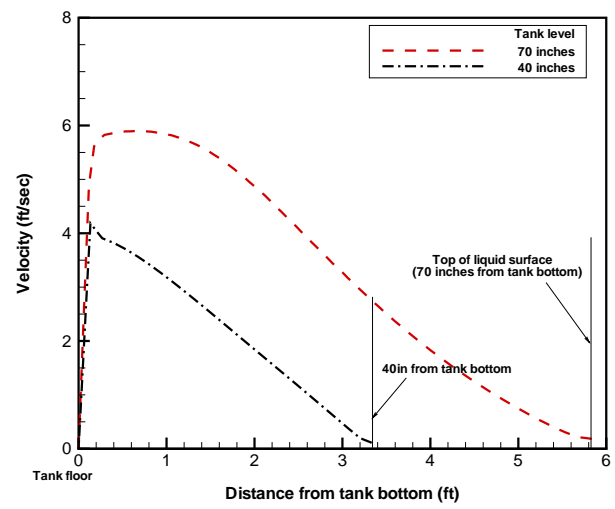

(33 $\mathrm{ft}$ from the pump)

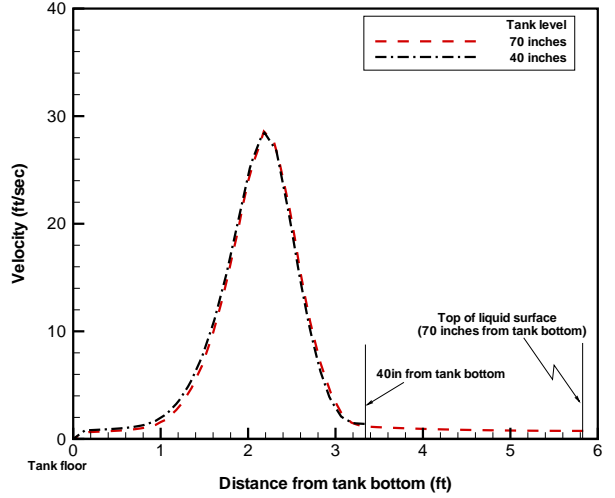

(5 $\mathrm{ft}$ from the pump)

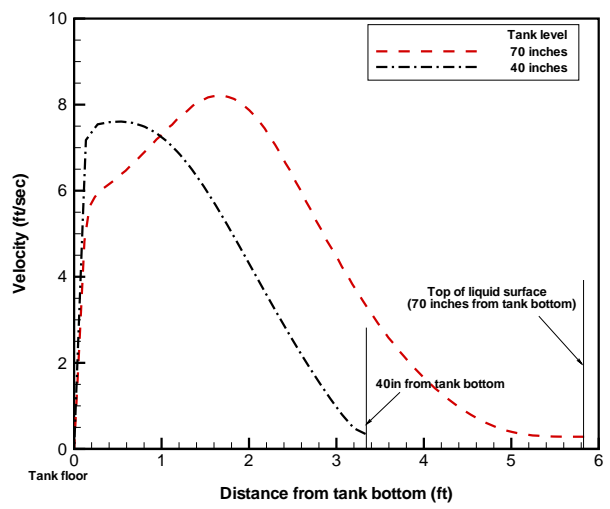

(20 $\mathrm{ft}$ from the pump)

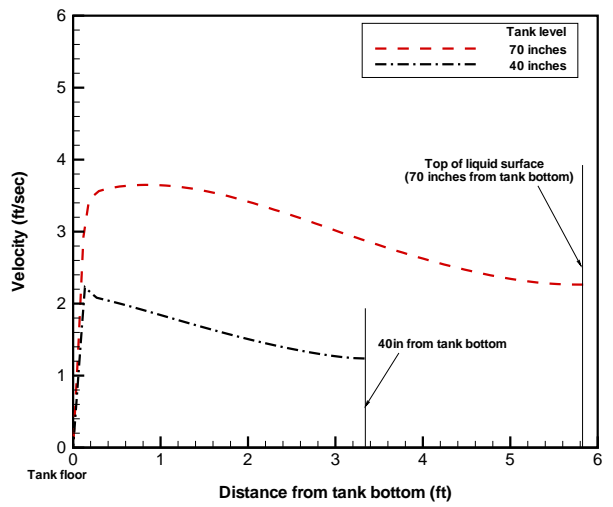

(40 ft from the pump)

Figure 27. Vertical velocity profiles of two different tank levels for various distances from the pump (pump nozzle is located $2.25 \mathrm{ft}$ from tank bottom) 


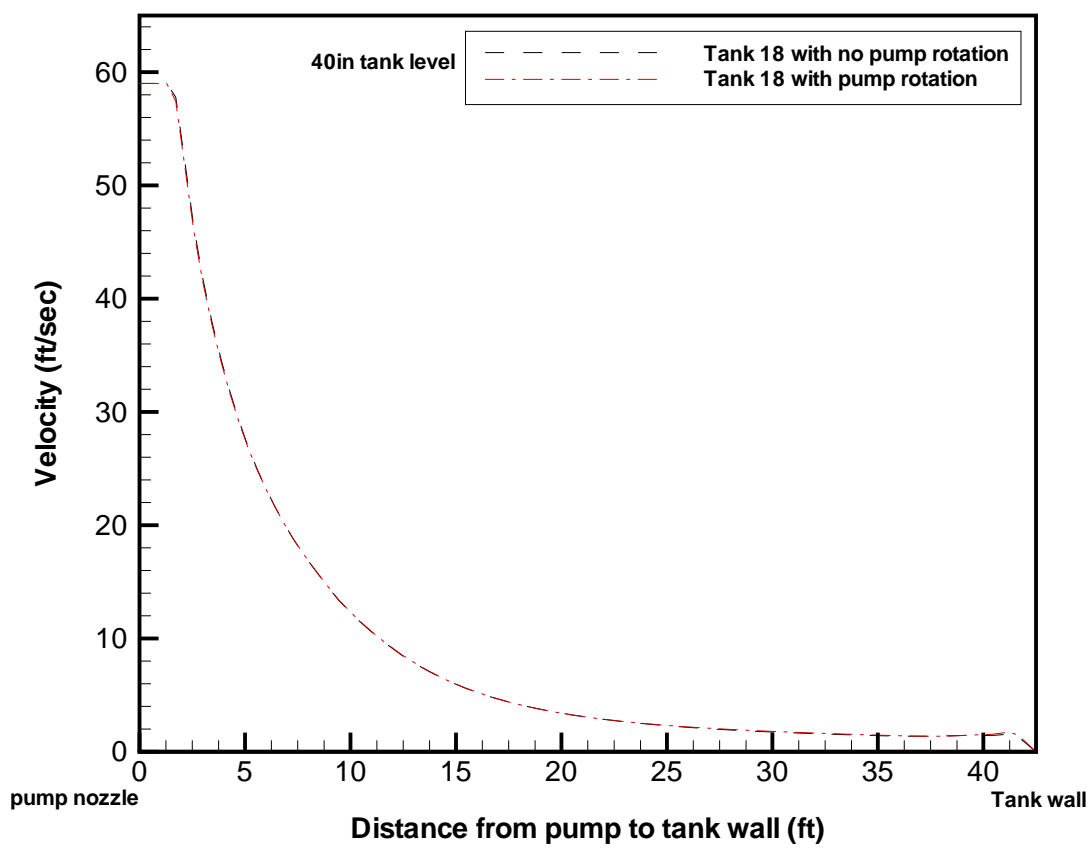

Figure 28. Downstream evolutions of Tank 18 with and without pump rotations for 40 in tank level at the discharge plane 27 inches above the tank bottom.

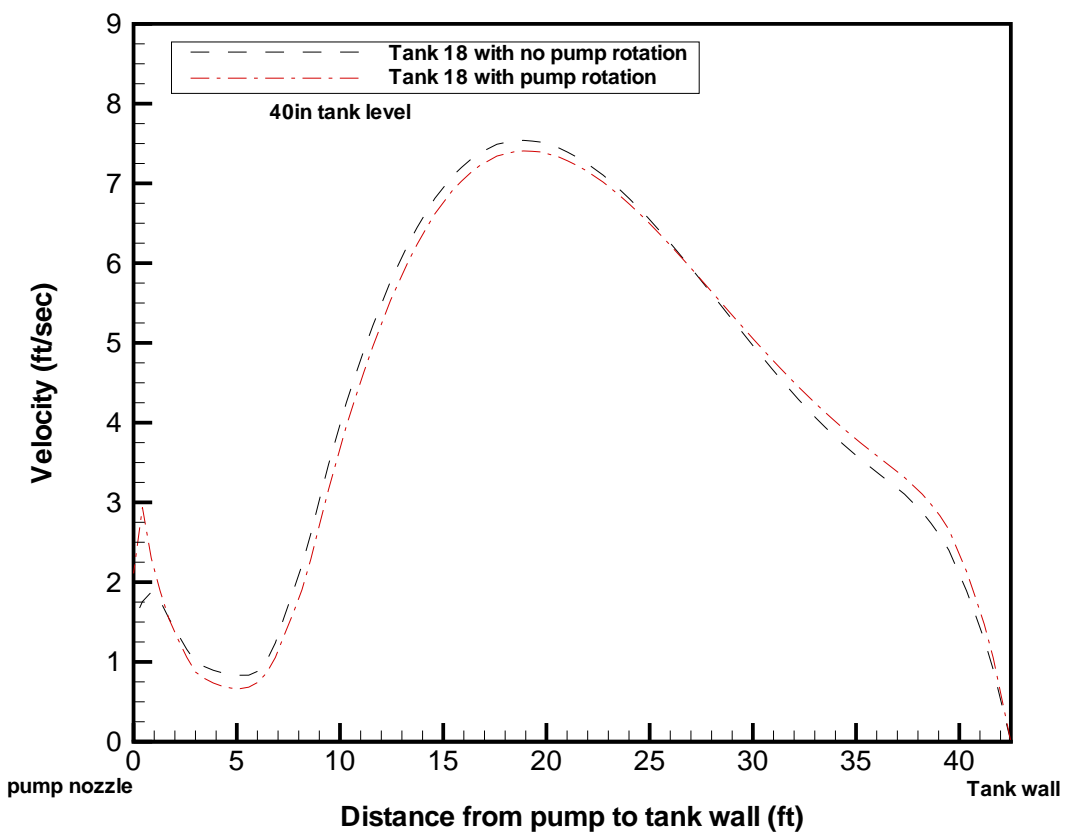

Figure 29. Downstream evolutions of Tank 18 with and without pump rotations for 40 in tank level at the discharge plane 3 inches above the tank bottom. 
Report: WSRC-TR-2001-00391

Date: $\quad 04 / 05 / 02$

Page: $\quad 42$ of 66
WESTINGHOUSE SAVANNAH RIVER COMPANY

PERFORMANCE ANALYSIS FOR MIXING PUMPS OF TANK 18

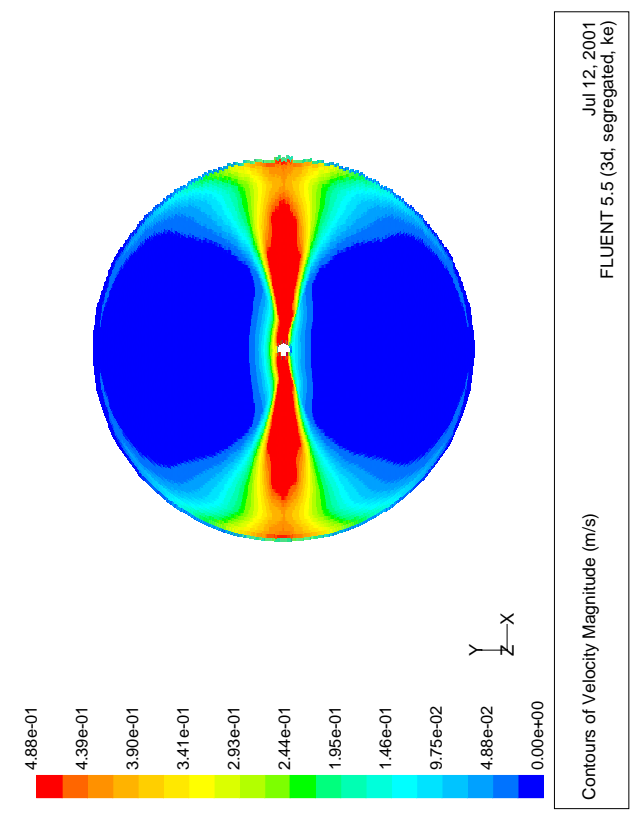

(no pump rotation for 40 in liquid level)

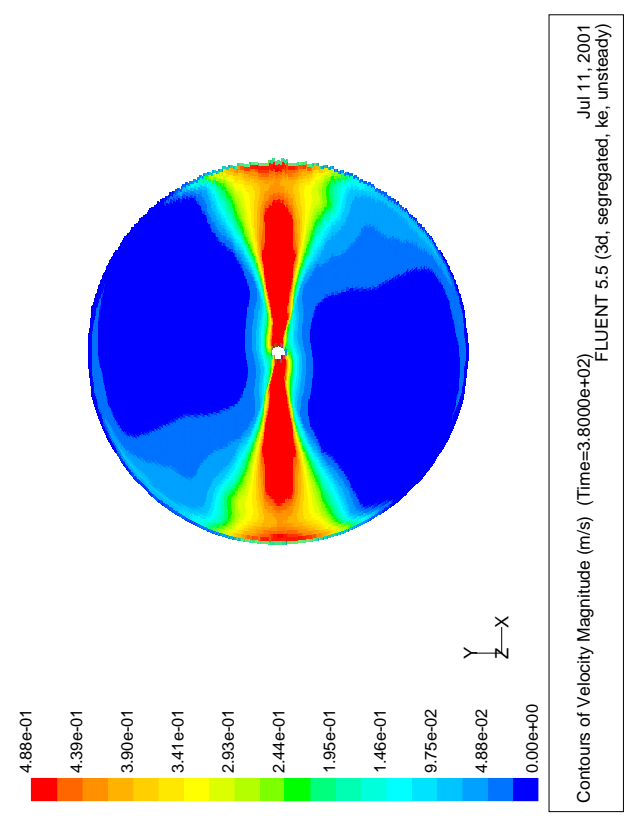

(pump rotation for 40 in liquid level)

Figure 30. Steady-state downstream evolutions of Tank 18 with and without pump rotations for 40 in tank level at the discharge plane 27 inches above the tank bottom.
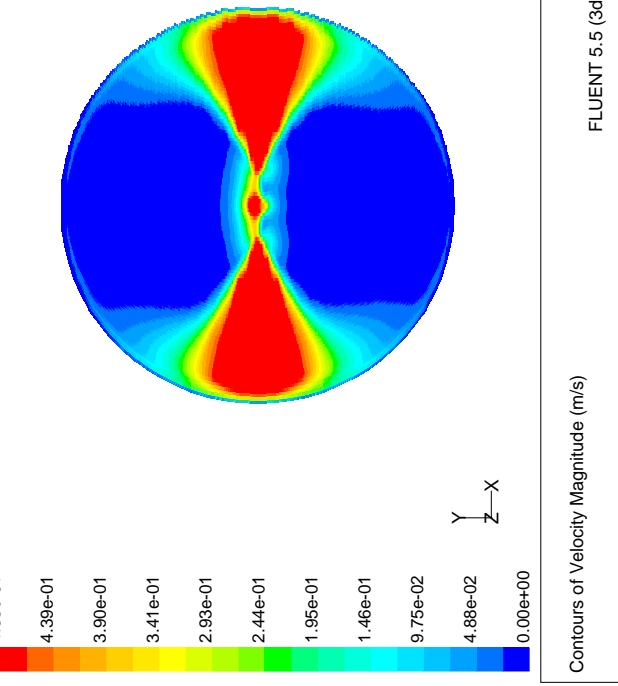

(no pump rotation for 40 in liquid level)
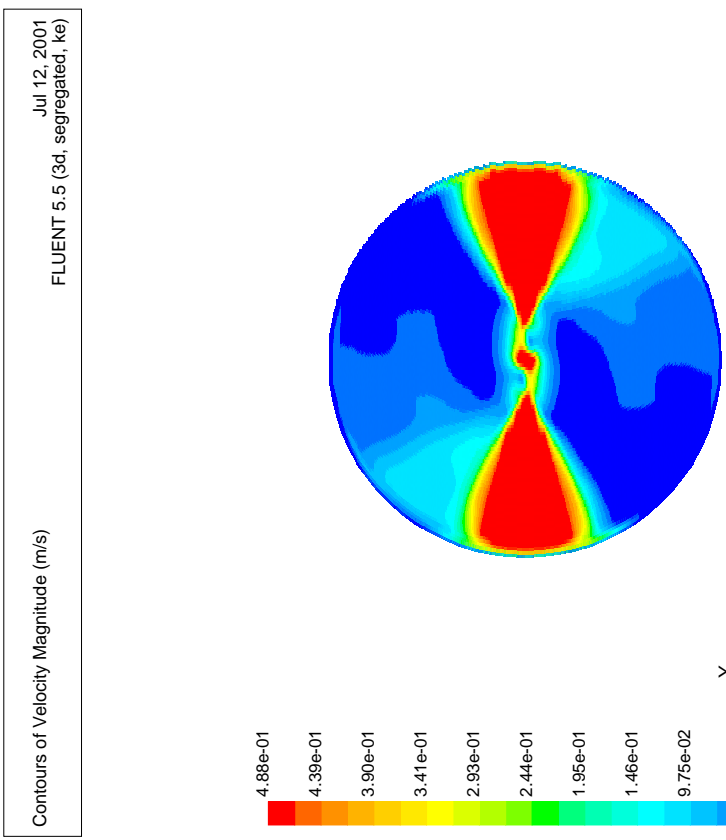

Figure 31. Steady-state downstream evolutions of Tank 18 with and without pump rotations for 40 in tank level at the discharge plane 3 inches above the tank bottom. 


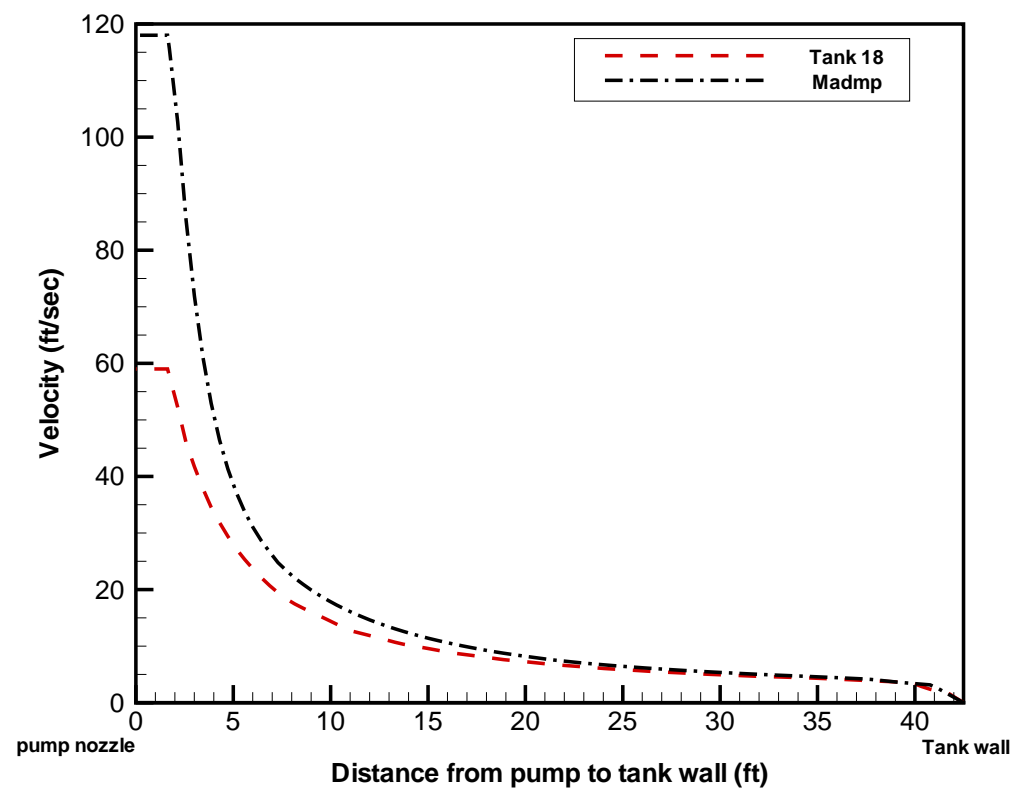

Figure 32. Downstream velocity profiles along the discharge directions of the nozzle planes of Tank 18 ADMP and MADMP mixers (The mapping name Tank 18 in the figure means Tank 18 operation with the existing ADMP.)

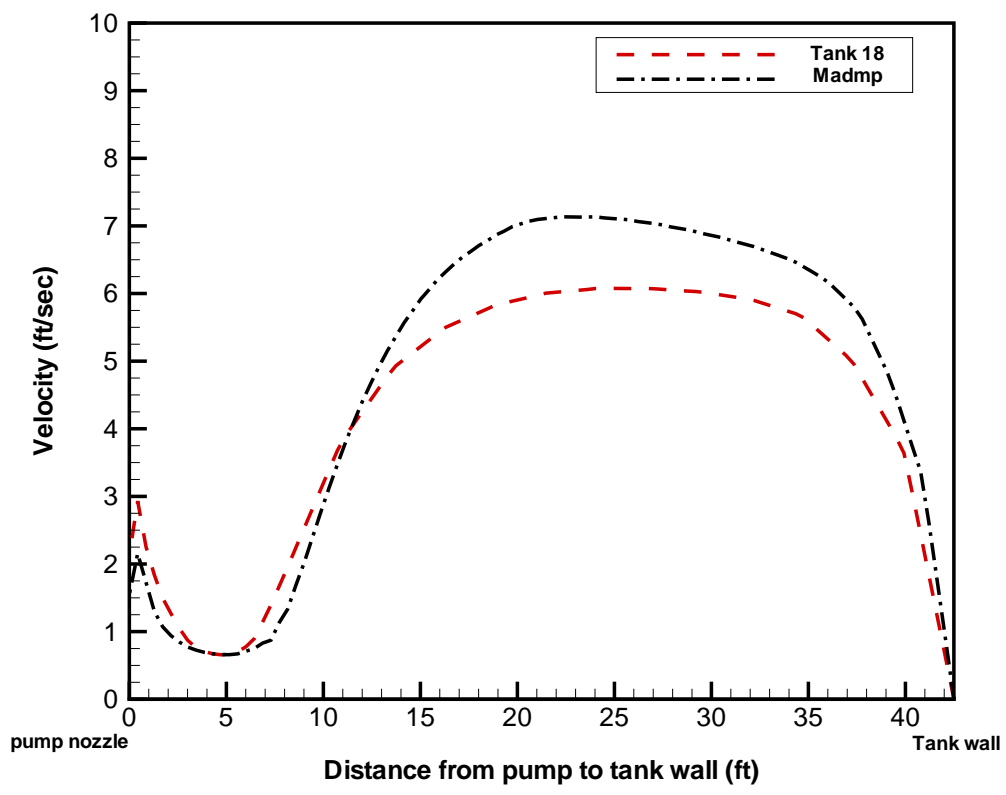

Figure 33. Horizontal velocity profiles along the downstream directions of the pump nozzles of Tank 18 with ADMP and MADMP mixers at the plane 3 in above the tank bottom (The mapping name Tank 18 in the figure means Tank 18 operation with the existing ADMP.) 
Report: WSRC-TR-2001-00391

Date: $\quad 04 / 05 / 02$

Page: $\quad 44$ of 66
WESTINGHOUSE SAVANNAH RIVER COMPANY

PERFORMANCE ANALYSIS FOR MIXING PUMPS OF TANK 18

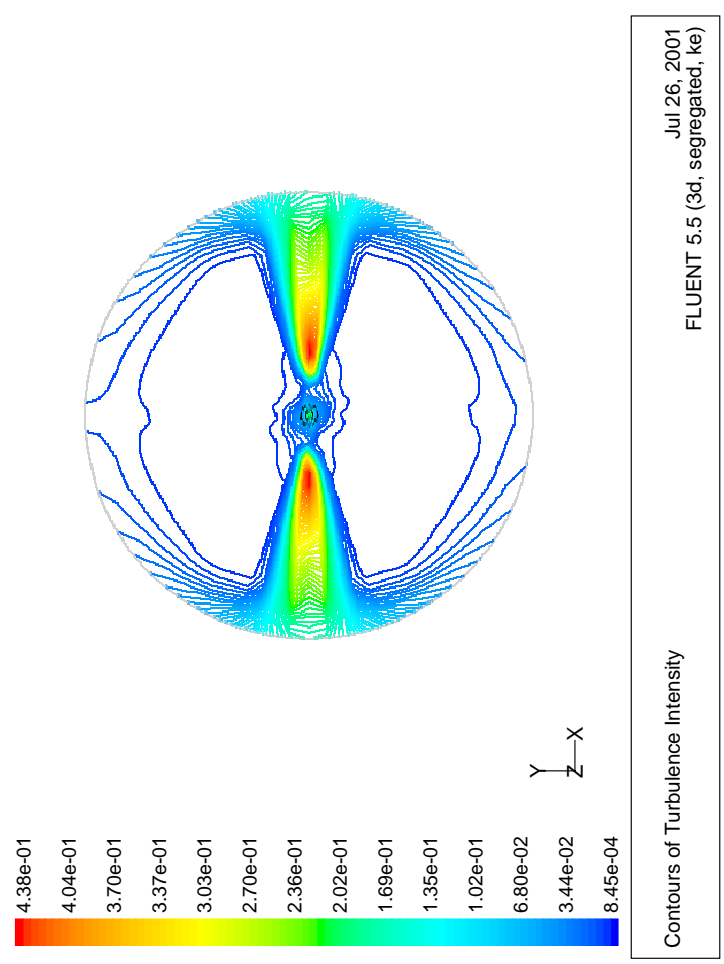

(Turbulence intensity contour plot for Tank 18 operation with ADMP mixer)

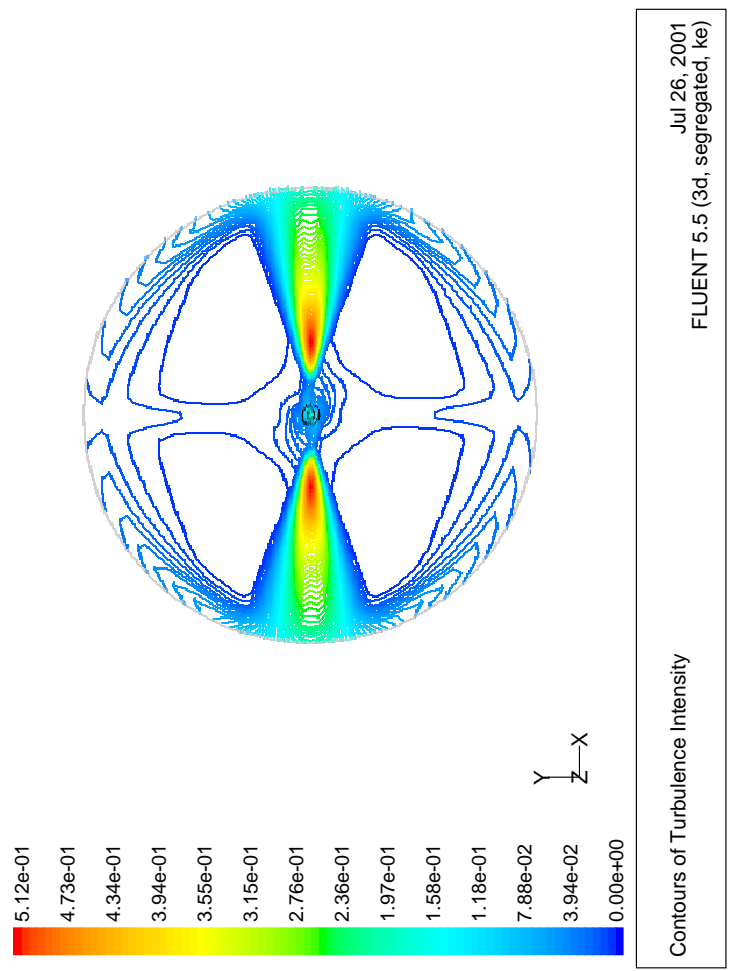

(Turbulence intensity contour plot for Tank 18 operation with MADMP mixer)

Figure 34. Comparison of turbulence intensity profiles for the Tank 18 operations with ADMP and MADMP mixers at the plane 3 in above the tank bottom 


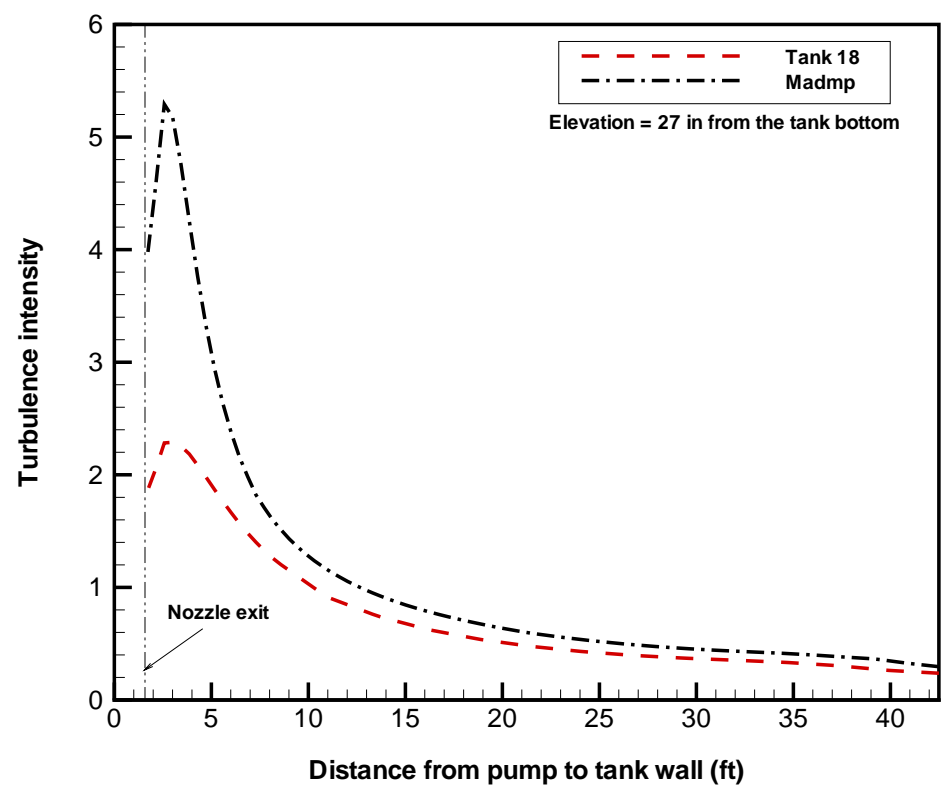

(Turbulence intensity profiles at 27 in elevation from the tank bottom)

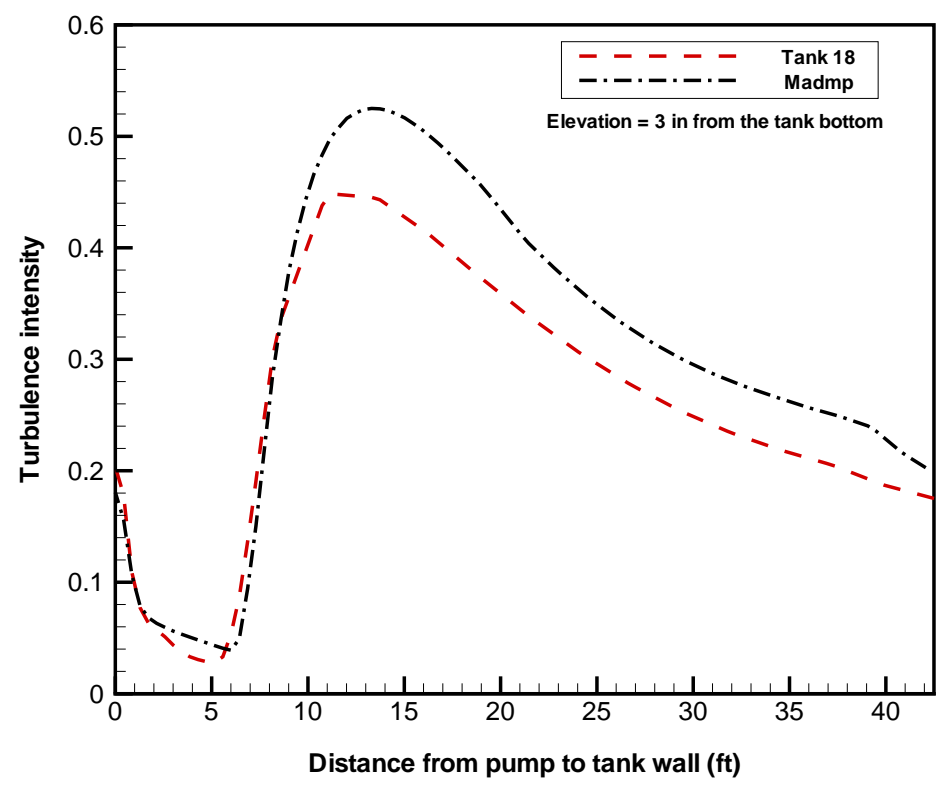

(Turbulence intensity profiles at 3 in elevation from the tank bottom)

Figure 35. Comparisons of turbulence intensity profiles for the Tank 18 operations with ADMP and MADMP mixers at the plane 3 in above the tank bottom (The mapping name Tank 18 in the figure means Tank 18 operation with the existing ADMP.) 


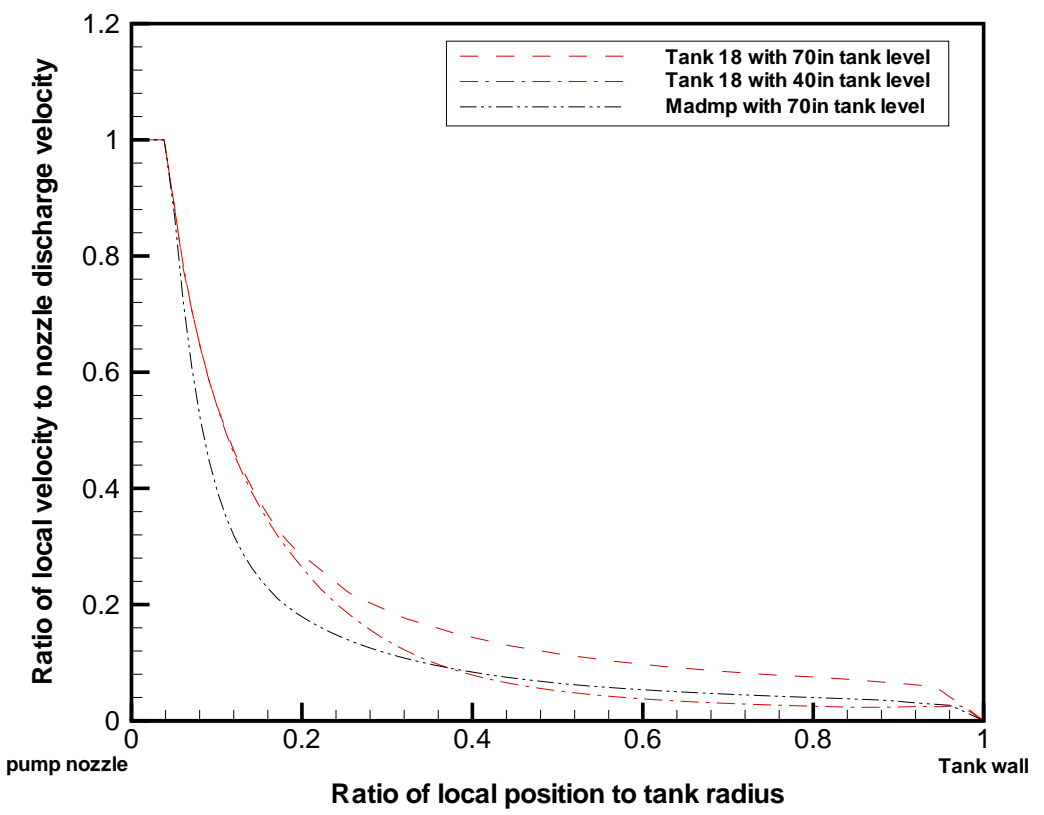

Figure 36. Nondimensional velocity distributions along the discharge direction of pump nozzle at the nozzle plane 27 in above the tank bottom (The mapping name Tank 18 in the figure means Tank 18 operation with the existing ADMP.)

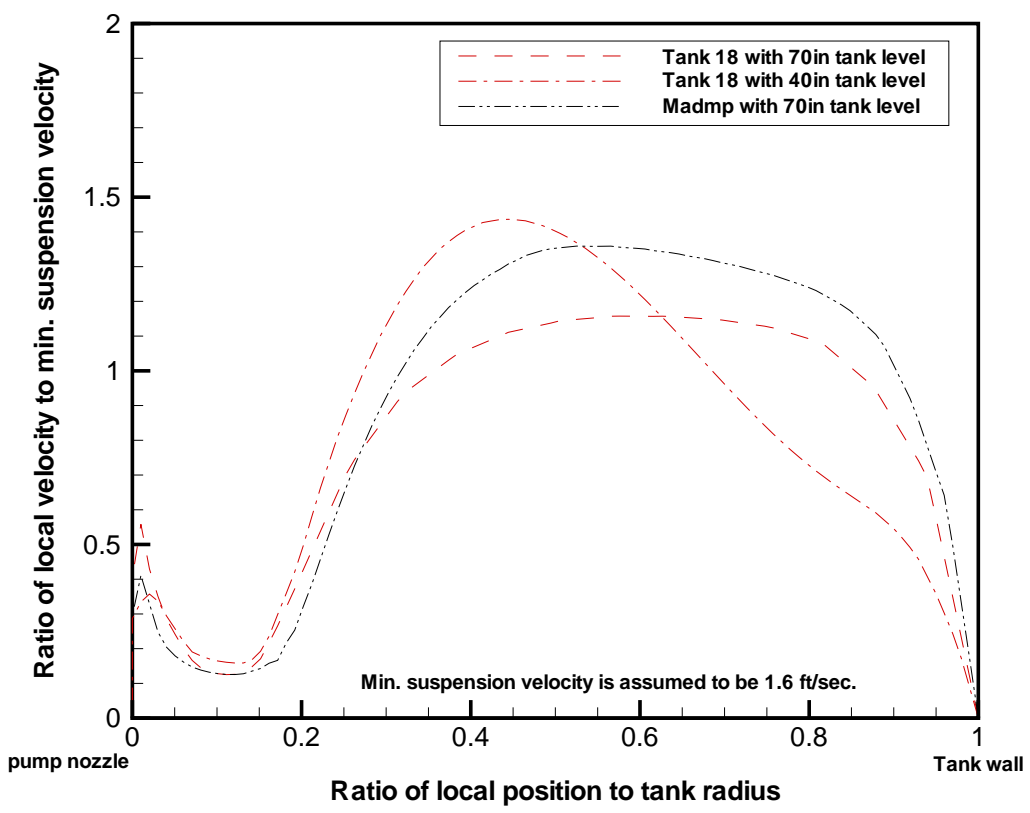

Figure 37. Nondimensional velocity distributions along the discharge direction of pump nozzle at the plane 3 in above the tank bottom (The mapping name Tank 18 in the figure means Tank 18 operation with the existing ADMP.) 


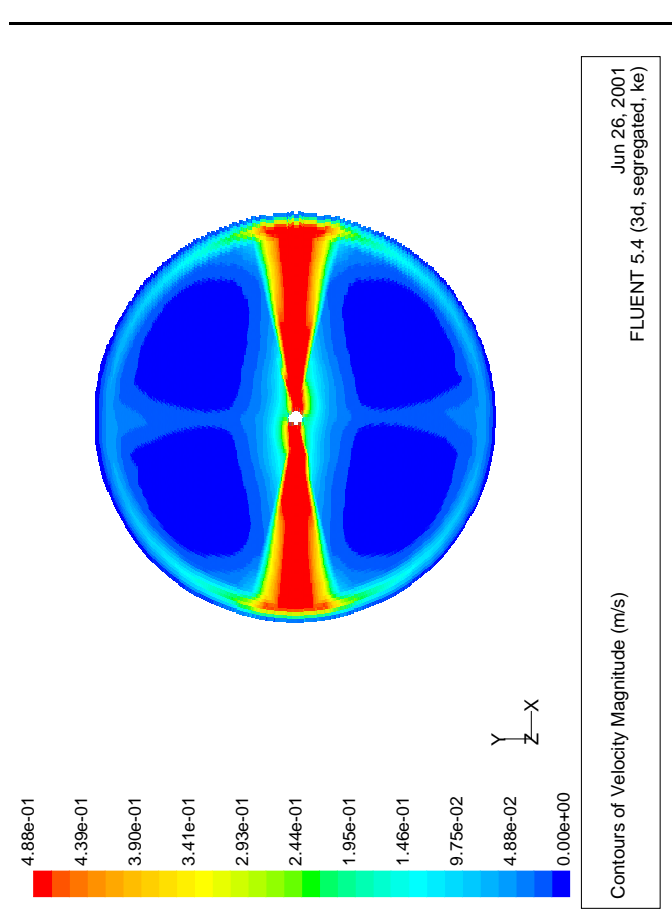

(Tank 18 with ADMP)
Page:
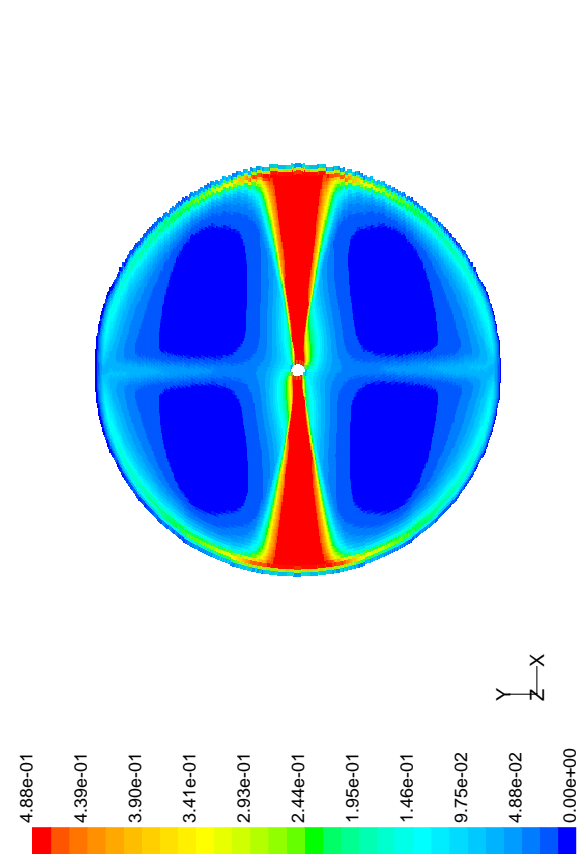

(Tank 18 with MADMP)

47 of 66

Figure 38. Comparison of flow evolutions induced by the Tank 18 ADMP and MADMP mixers with 70 in tank levels on the discharge plane 27 in above the tank bottom
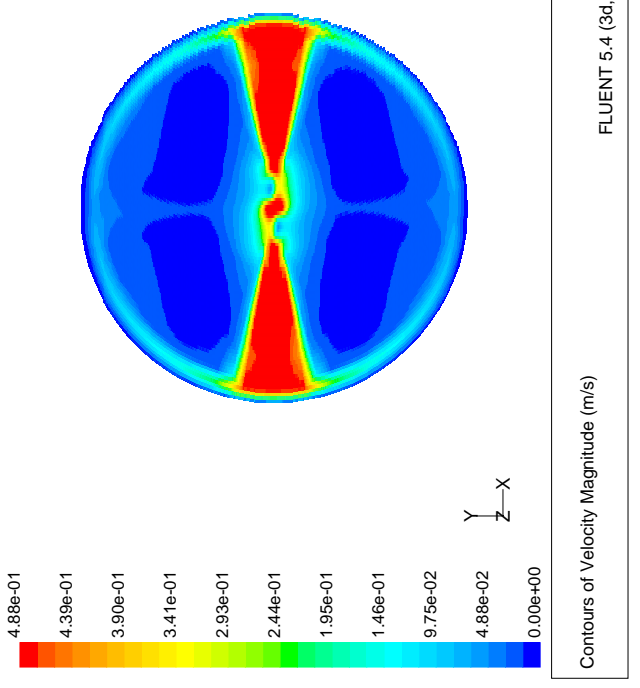

(Tank 18 with ADMP)

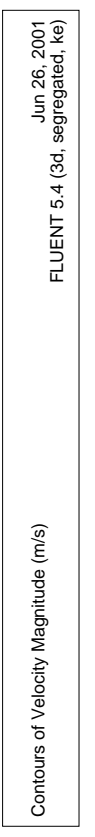

Figure 39. Comparison of flow evolutions induced by the Tank 18 ADMP and MADMP mixers with 70 in tank levels on the horizontal plane 3 in above the tank bottom 
Report: WSRC-TR-2001-00391

Date: $\quad 04 / 05 / 02$

Page: $\quad 48$ of 66

WESTINGHOUSE SAVANNAH RIVER COMPANY

PERFORMANCE ANALYSIS FOR MIXING PUMPS OF TANK 18

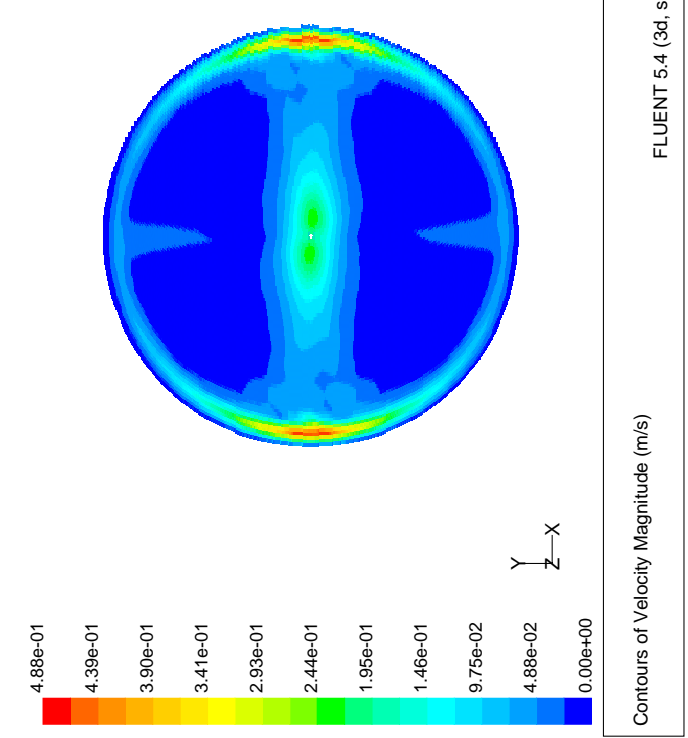

(Tank 18 with ADMP)

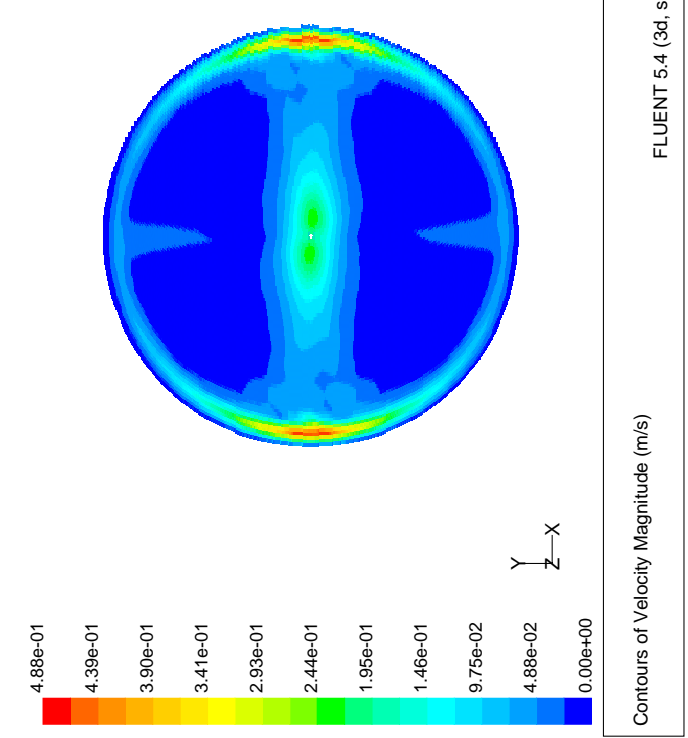

Figure 40. Comparison of flow evolutions induced by the Tank 18 ADMP and MADMP mixers at the top surfaces of 70 in tank levels

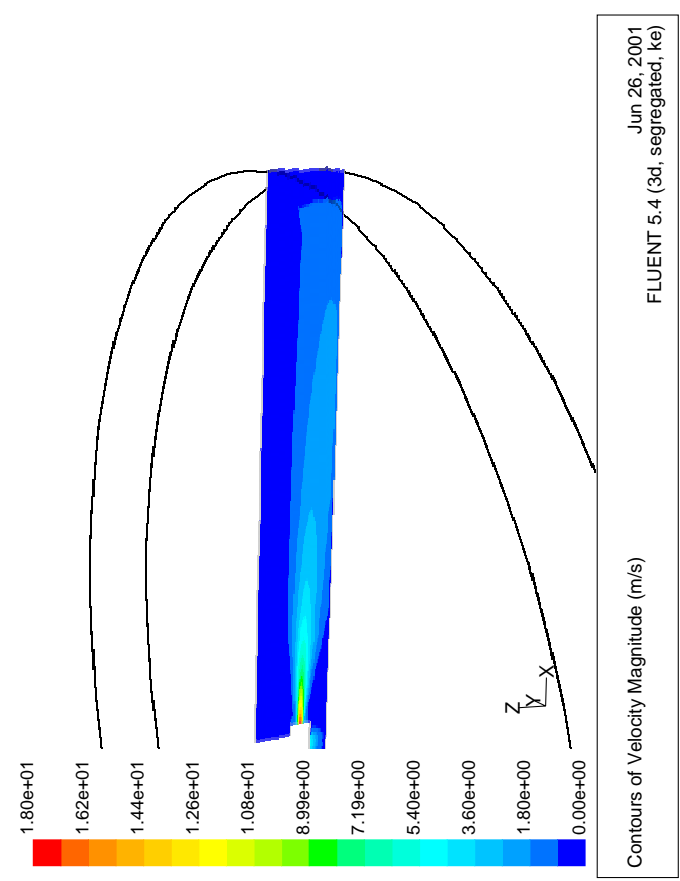

(Tank 18 with ADMP)

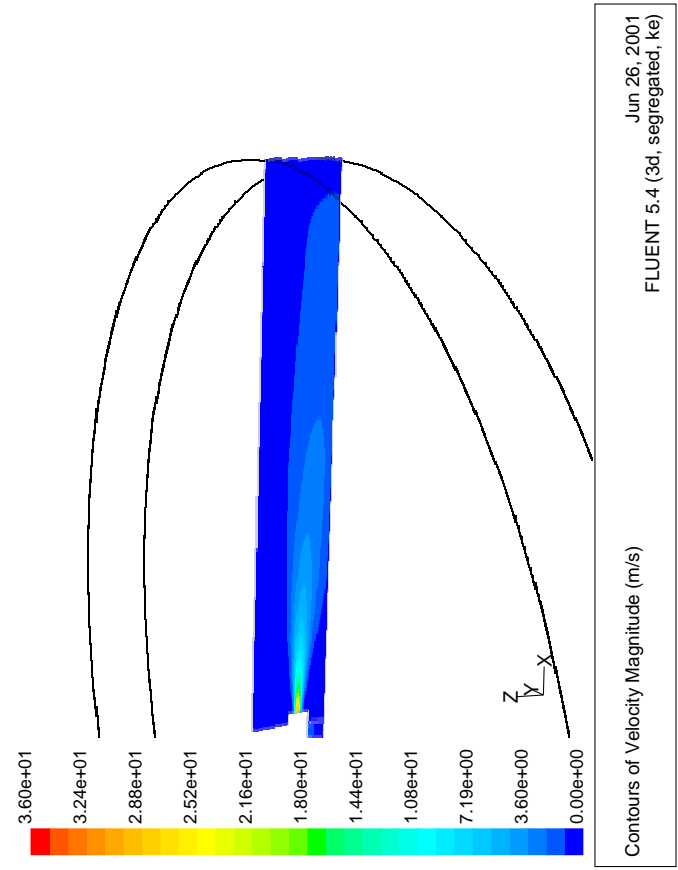

(Tank 18 with MADMP)

Figure 41. Comparison of velocity contour plots induced by the Tank 18 ADMP and MADMP mixers at the center planes of 70 in tank levels 


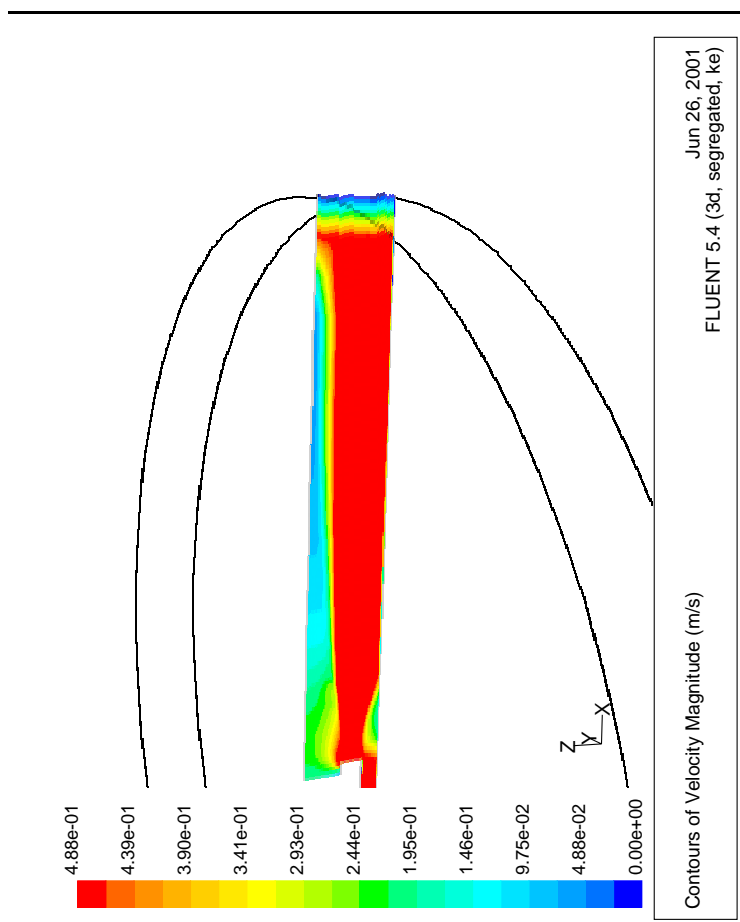

(Tank 18 with ADMP)
Page: 49 of 66

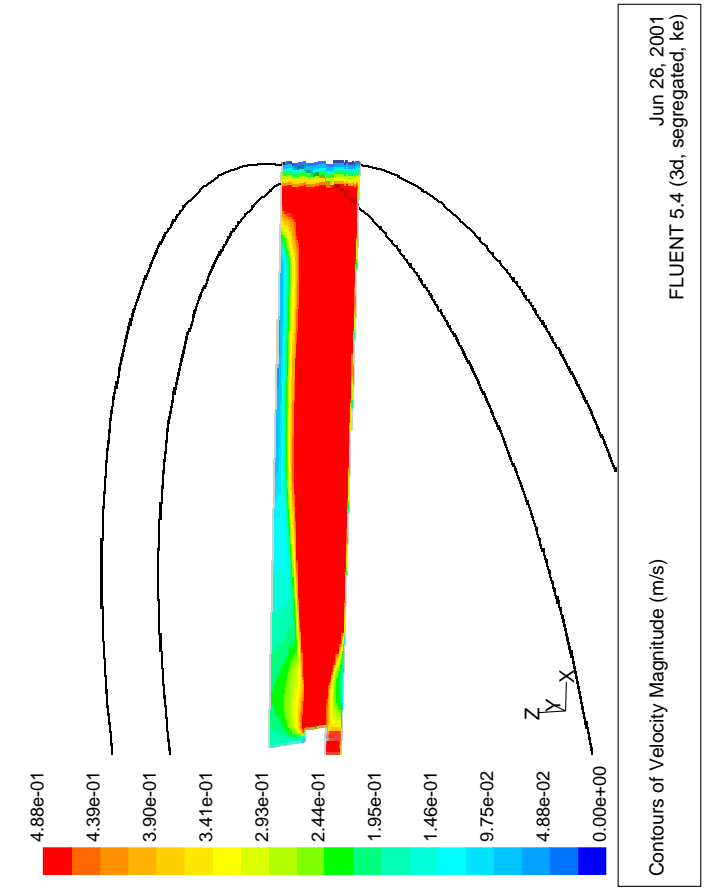

(Tank 18 with MADMP)

Figure 42. Comparison of suspended zones of zeolites induced by the Tank 18 ADMP and MADMP mixers at the center planes of 70 in tank levels

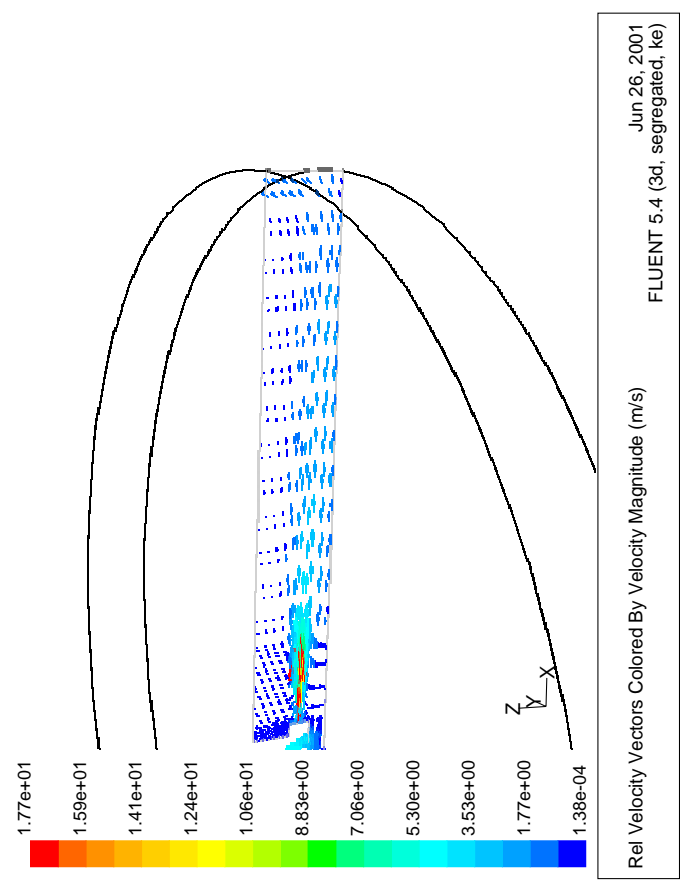

(Tank 18 with ADMP)

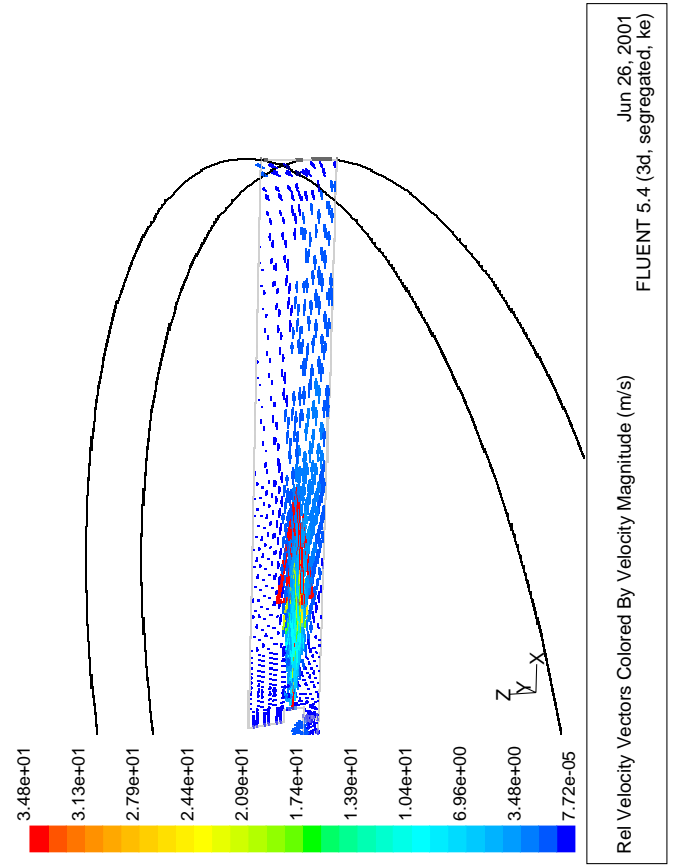

(Tank 18 with MADMP)

Figure 43. Comparison of flow patterns induced by the Tank 18 ADMP and MADMP mixers at the center planes of 70 in tank levels 


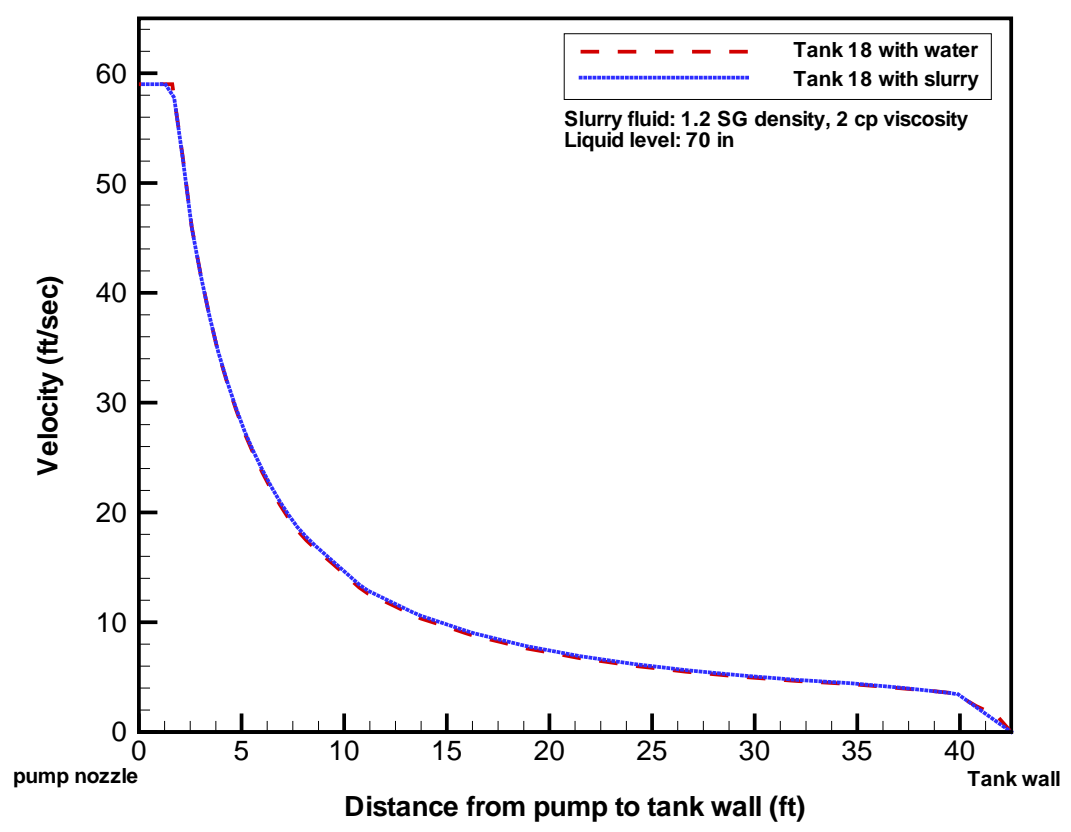

(velocity distributions at the level of nozzle exit)

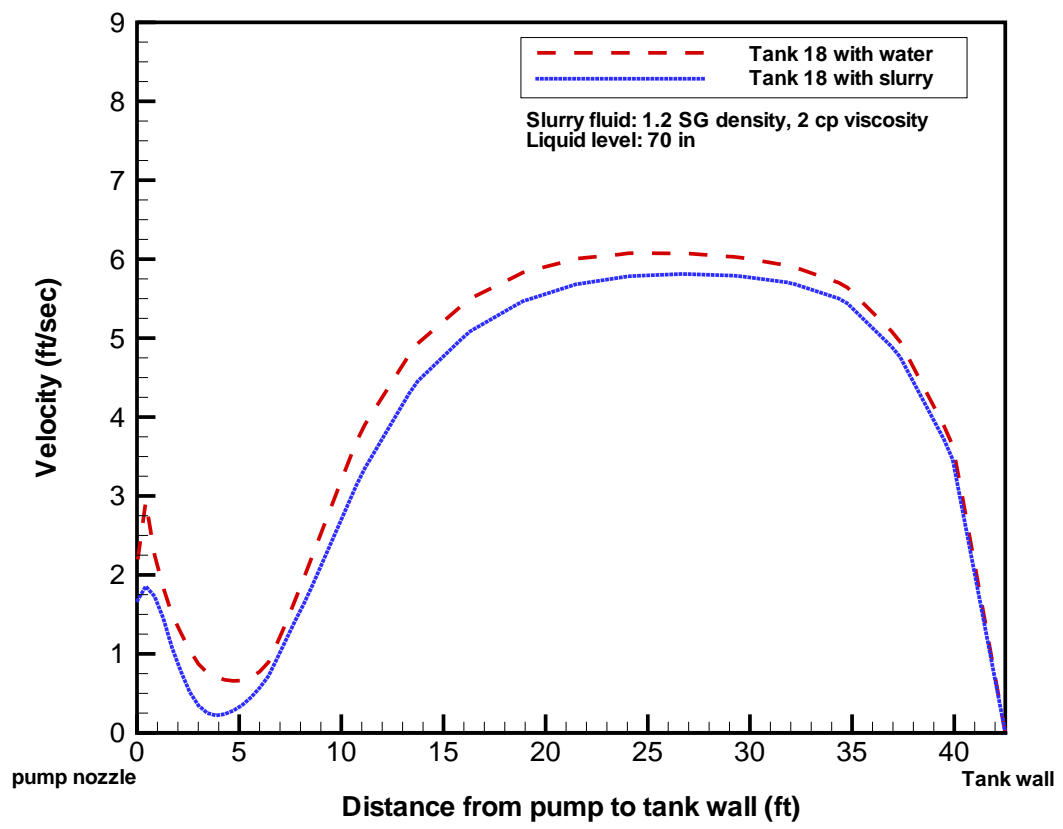

(velocity distributions at the 3 in elevation from the tank bottom)

Figure 44. Comparison of flow evolutions with two different mixing fluids induced by the Tank 18 ADMP mixer at the 27 in (nozzle exit level) and 3 in elevations from the tank bottom 


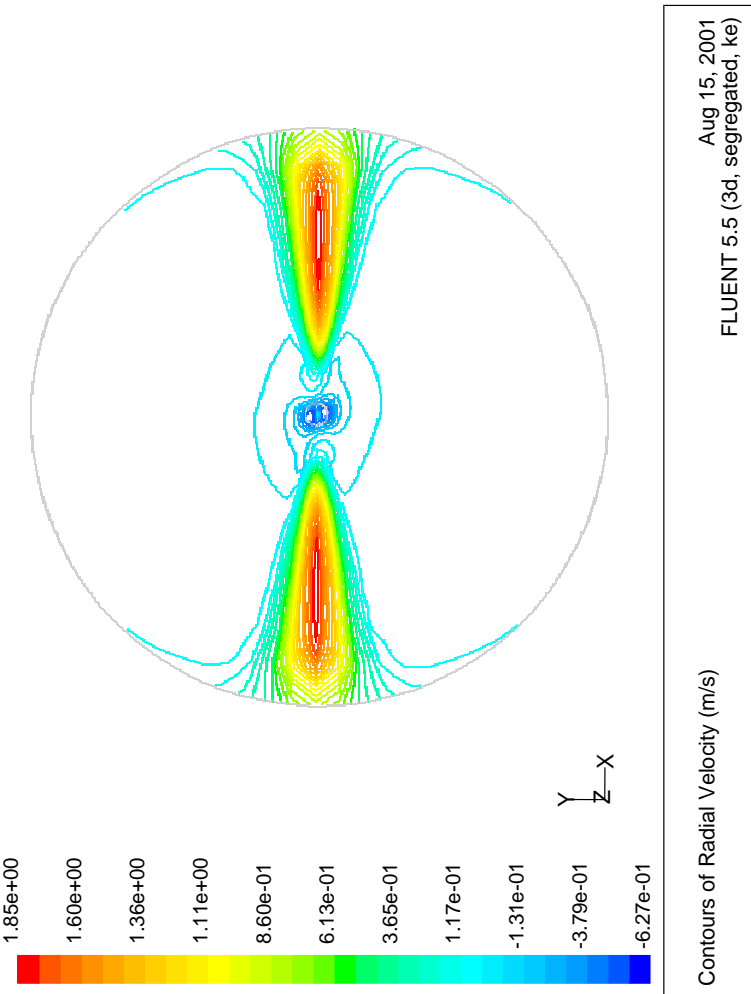

(Water flow evolutions at 3 in elevation from the tank bottom)

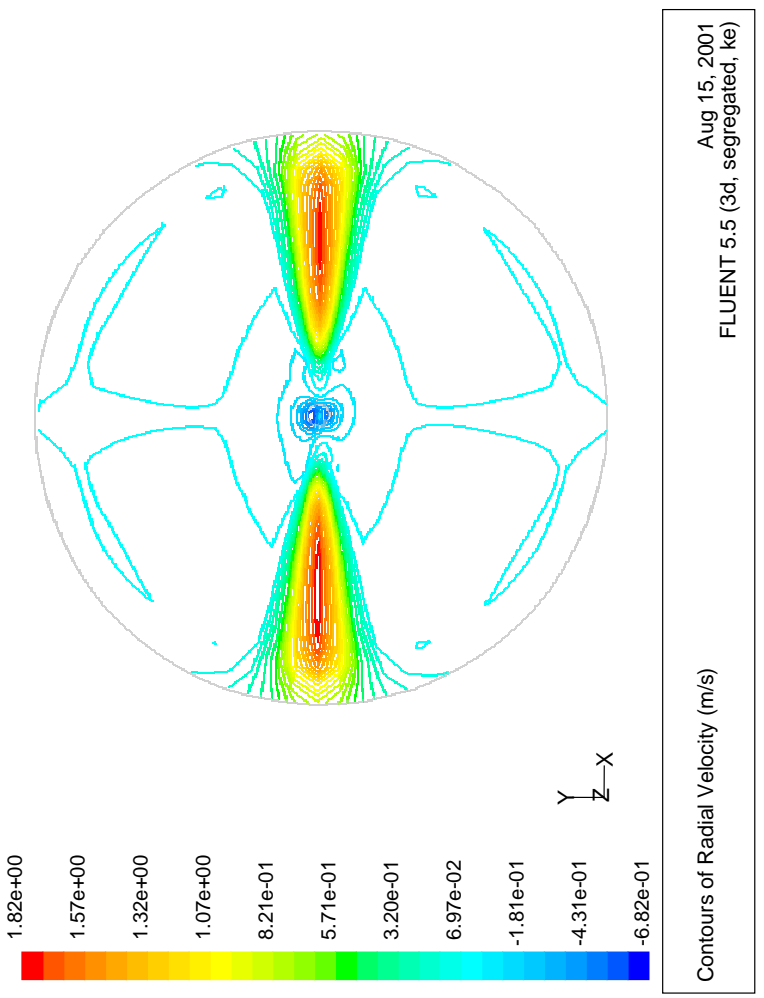

(Slurry flow evolutions at 3 in elevation from the tank bottom)

Figure 45. Comparison of flow evolutions with water and slurry fluids induced by the Tank 18 ADMP mixer at the 3 in elevations from the tank bottom 


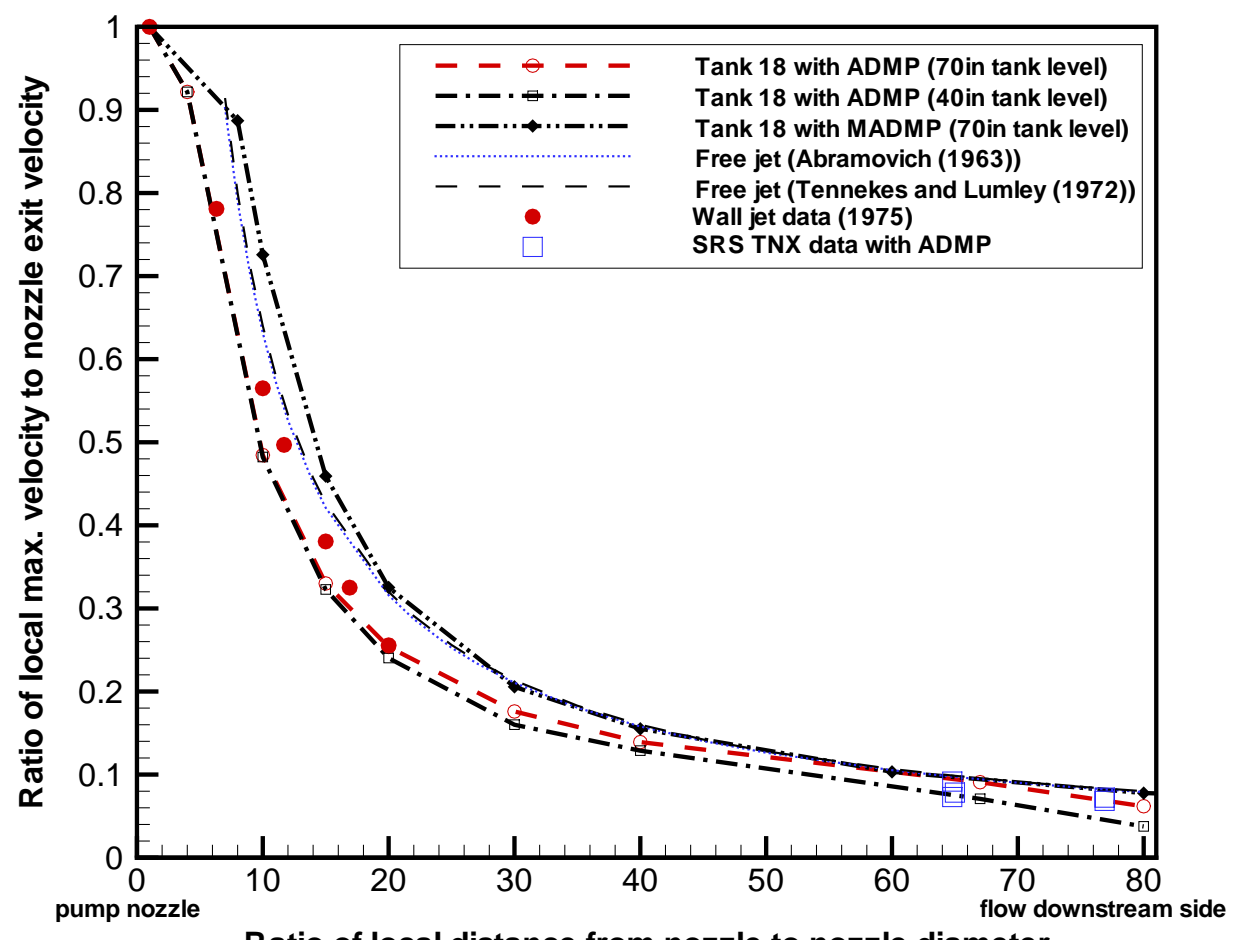

Ratio of local distance from nozzle to nozzle diameter

Figure 46. Comparisons of steady-state non-dimensional velocity profiles of Tank 18 at the discharge plane of ADMP mixer 27 in above tank bottom with literature data 

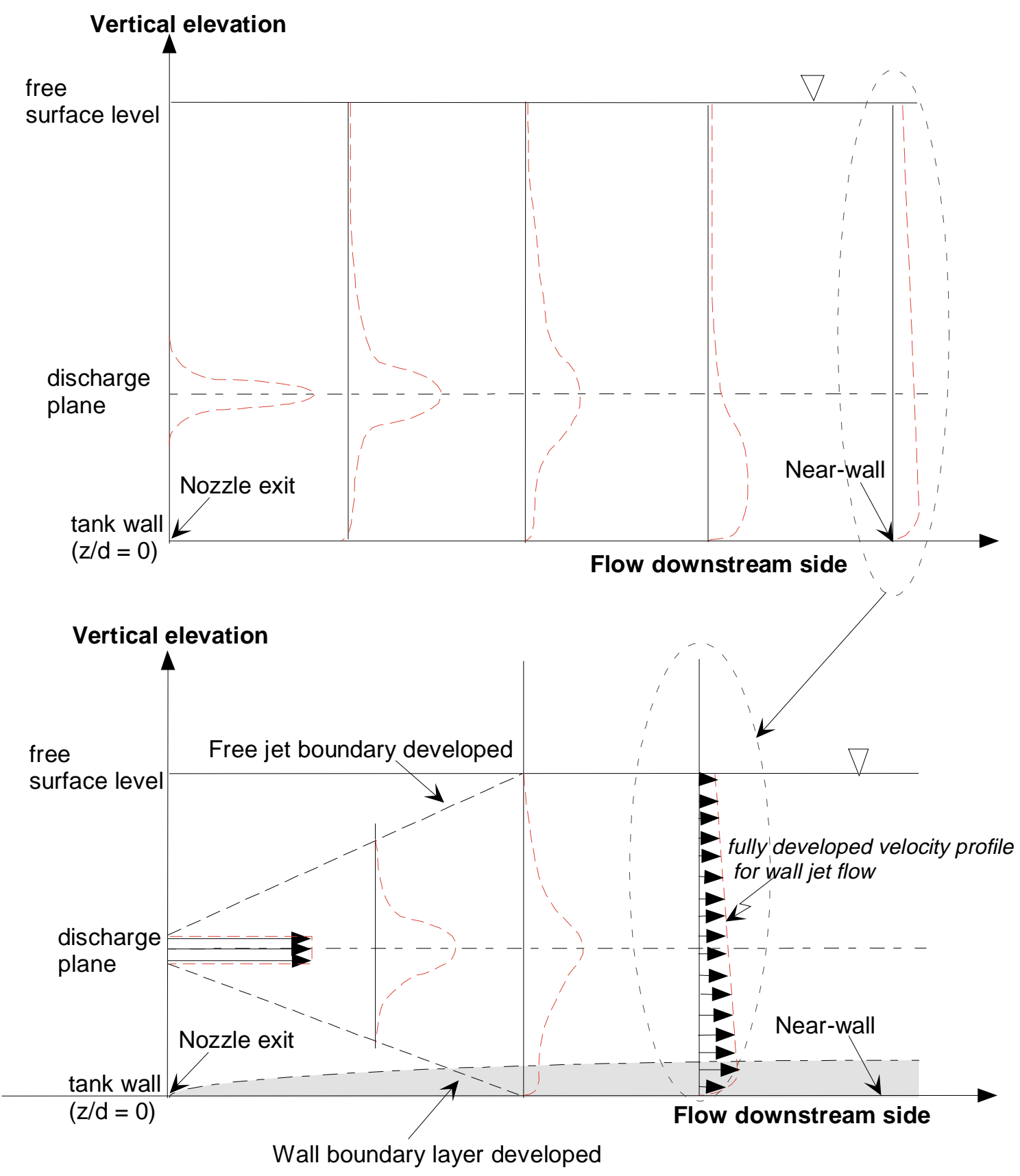

Figure 47. Typical velocity profiles in the direction perpendicular to the free surface from the modeling results of Tank 18 mixing simulations. 


\section{Page: $\quad 54$ of 66}

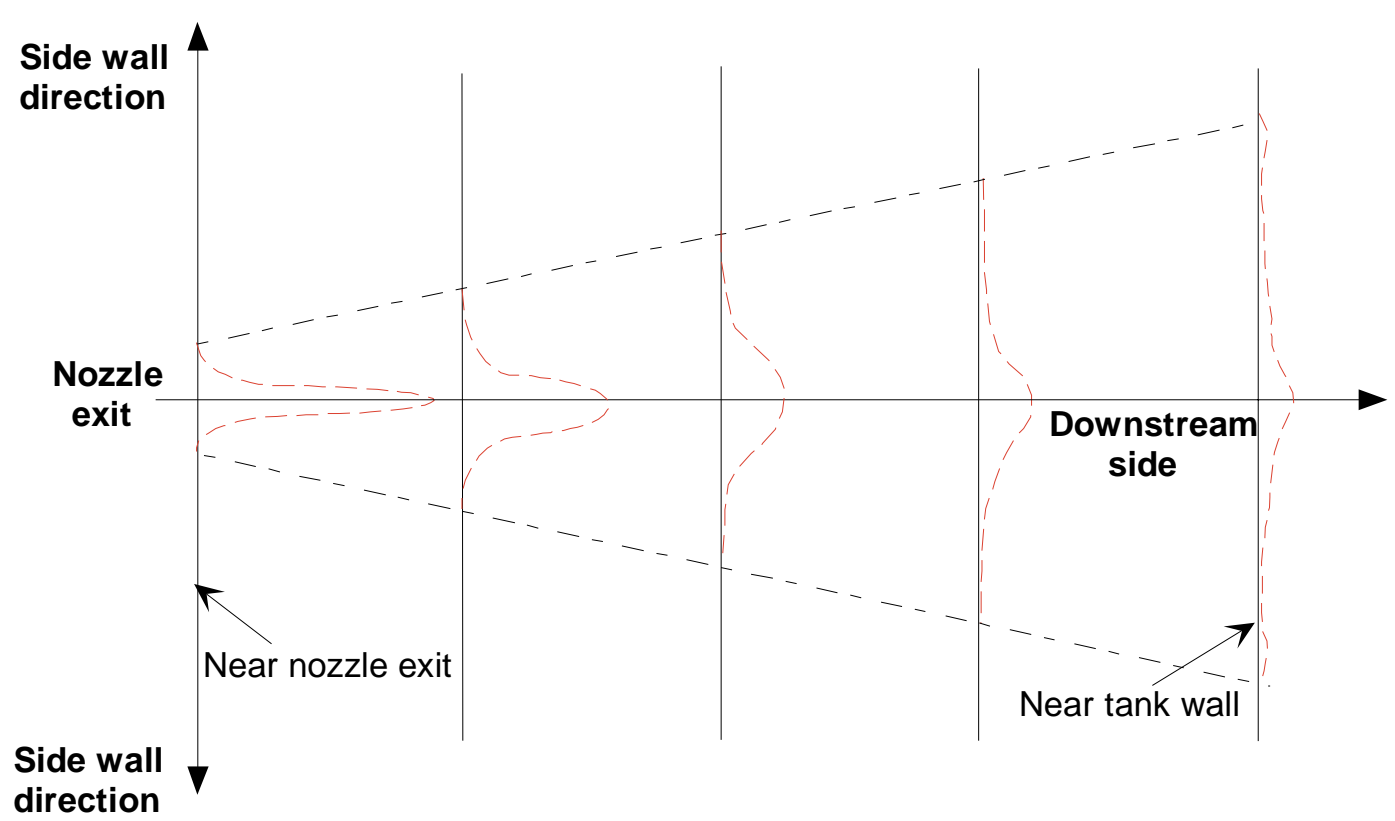

Figure 48. Typical velocity profiles in the direction parallel to the free surface from the modeling results of Tank 18 mixing simulations.

\section{Summary and Conclusions}

TNX full tank and Tank 18 simulation models with ADMP or MADMP mixers have been developed. Calculations have been performed to benchmark the models with TNX test data and to assess the efficiency of sludge suspension and removal operations in Tank 18 during steady-state and transient pump operations. Reference design and operating conditions were used as shown in Tables 3 and 4 . Solid obstructions other than the pump housing and the 16" riser, and free surface motion of the tank liquid were neglected.

A three-dimensional analysis with a two-equation turbulence model was performed with FLUENT $^{T M}$, a commercial computational fluid dynamics (CFD) code. A two-dimensional approach was also used as a scoping analysis to examine multi-dimensional effects of fluid motion on the flow circulation pattern in the tank. The computed results were validated with TNX test and literature data. Rotational effects of the pump were considered to estimate the impact on the sludge suspension and removal assuming that local fluid velocity can be used as a measure of slurrying and mixing efficiency. For a minimum suspension velocity of $2.27 \mathrm{ft} / \mathrm{sec}$, the results indicated that the existing ADMP mixer would provide adequate sludge removal from the tank with a 70 in liquid level except for a wall boundary of about $2 \mathrm{ft}$.

The CFD simulation results for the ADMP mixer showed that steady-state flow patterns were reached in about 60 seconds after starting the pump. As expected, the results also showed that when the pump was rotated in a continuous and one-way direction, the operational time to reach steady-state conditions was much longer. In addition, when 
the pump is off-center, times to reach steady-state flow patterns are much longer than the case with the pump located at the tank center.

The main conclusions are as follows:

- Model predictions agree with test data within about 25\%. In the velocity ranges where sludge removal is required, the model provides a conservative estimate when compared to actual test data. The predictions are in good agreement with wall jet data available in the literature.

- The difference between a fixed pump and a rotating pump is small, and is well within the uncertainty of the present calculations. The pump with rotation appears to be somewhat better than the one with no rotation in terms of waste removal and suspension capabilities, largely because of secondary flows. The effect of pump rotation is more pronounced when the pump is located off-center and the tank liquid level is lower.

- Higher tank level results in better performance for suspending and removing the sludge for the given design and operating conditions of Tank 18.

- A smaller nozzle size with an identical $U_{0} d_{0}$ has better performance for suspending and removing the sludge for the given design and operating conditions of Tank 18. The MADMP mixer has the best performance among the cases considered in terms of sludge removal capacity.

- The computational results for two different fluids, water and a typical slurry (1.2 specific gravity, $2 \mathrm{cp}$ ), show that the maximum clearing distance is not sensitive to the slurry fluid properties. Therefore, all the flow pattern results based on water are valid for slurry flow in Tank 18.

- The results indicate that local velocities adjacent to the tank wall are potentially lower than those needed to remove sludge. The velocities are high enough to indicate that suspended zeolite will probably be swept aside.

- An approximate comparison (Appendix B) of results and observations from Tank 8 to the Tank 18 calculations documented here indicates that about 2000 gallons of sludge and zeolite mixture might lie in the bottom corner of Tank 18 beyond the reach of the ADMP. 
Report: WSRC-TR-2001-00391

Date: $\quad 04 / 05 / 02$

Page: $\quad 56$ of 66
WESTINGHOUSE SAVANNAH RIVER COMPANY

PERFORMANCE ANALYSIS FOR MIXING PUMPS OF TANK 18

(This Page Intentionally Left Blank) 


\section{References}

1. R. A. Leishear, e-mail on design information of ADMP (LPI\#91370), April 23, 2001.

2. HLW Technical Request Form, HLE-TTR-2001-049, Rev. 1, May 29, 2001.

3. N. V. Chadrasekhara Swamy and P. Bandyopadhyay, "Mean and Turbulence Characteristics of Three-Dimensional Wall Jets", Journal of Fluid Mechanics, Vol. 71, Part 3, pp. 541-562 (1975).

4. FLUENT, Fluent, Inc. (1998).

5. F. A. Zenz and D. F. Othmer, Fluidization and Fluid-Particle Systems, Chapter 6, Reinhold Publishing Corppration, New York (1960).

6. S. Y. Lee and R. A. Dimenna, "Validation Analysis for the Calculation of a Turbulent Free Jet in water Using CFDS-FLOW3D and FLUENT (U)", WSRC-TR95-0170 (May 1995).

7. C. K. Madina and L. P. Bernal of F, "Interaction of a Turbulent Round Jet with the Free surface”, Journal of Fluid Mechanics, Vol. 261, pp. 305-332 (1994)

8. Personal Communications with R. A. Leishear, April 21, 2001

9. Abramovich, G. N., "The Theory of Turbulent Jets", The MIT Press, Cambridge, MA, 1963.

10. H. Schlichting, Boundary Layer Theory, McGraw-Hill Book Company, New York (1967).

11. Personal communications with Marsh-McBirney, Inc.,

Company Address: 4539 Metropolitan Ct., Frederick, Maryland 21704, Phone Number: (800) 368-2723, Fax Number: (301) 874-2172

e-mail: www.Marsh-McBirney.com

12. W. M. Rohsenow and H. Y. Choi, Heat, Mass, and Momentum Transfer, PrenticeHall, Inc., New Jersey (1961).

13. H. Tennekes and J. L. Lumley, A First Course in Turbulence, The MIT Press, Cambridge, MA, 1972.

14. B. V. Churnetski, "Effective Cleaning Radius Studies", Memorandum, DPST-81282, February 19, 1981.

15. J. H. Perry, Chemical Engineers' Handbook, Fourth Edition, McGraw-Hill Book Co, New York.

16. E. J. Freed and O. S. Mukherjee, "Tank 8 Waste Removal Operating Plan", UESR-F-00009, Rev. 5, April 3, 2001. 
Report: WSRC-TR-2001-00391

Date: $\quad 04 / 05 / 02$

Page: $\quad 58$ of 66
WESTINGHOUSE SAVANNAH RIVER COMPANY

PERFORMANCE ANALYSIS FOR MIXING PUMPS OF TANK 18

(This Page Intentionally Left Blank) 


\section{Appendix A: Mapping of Velocity Measurement Sensor and Benchmarking Results}

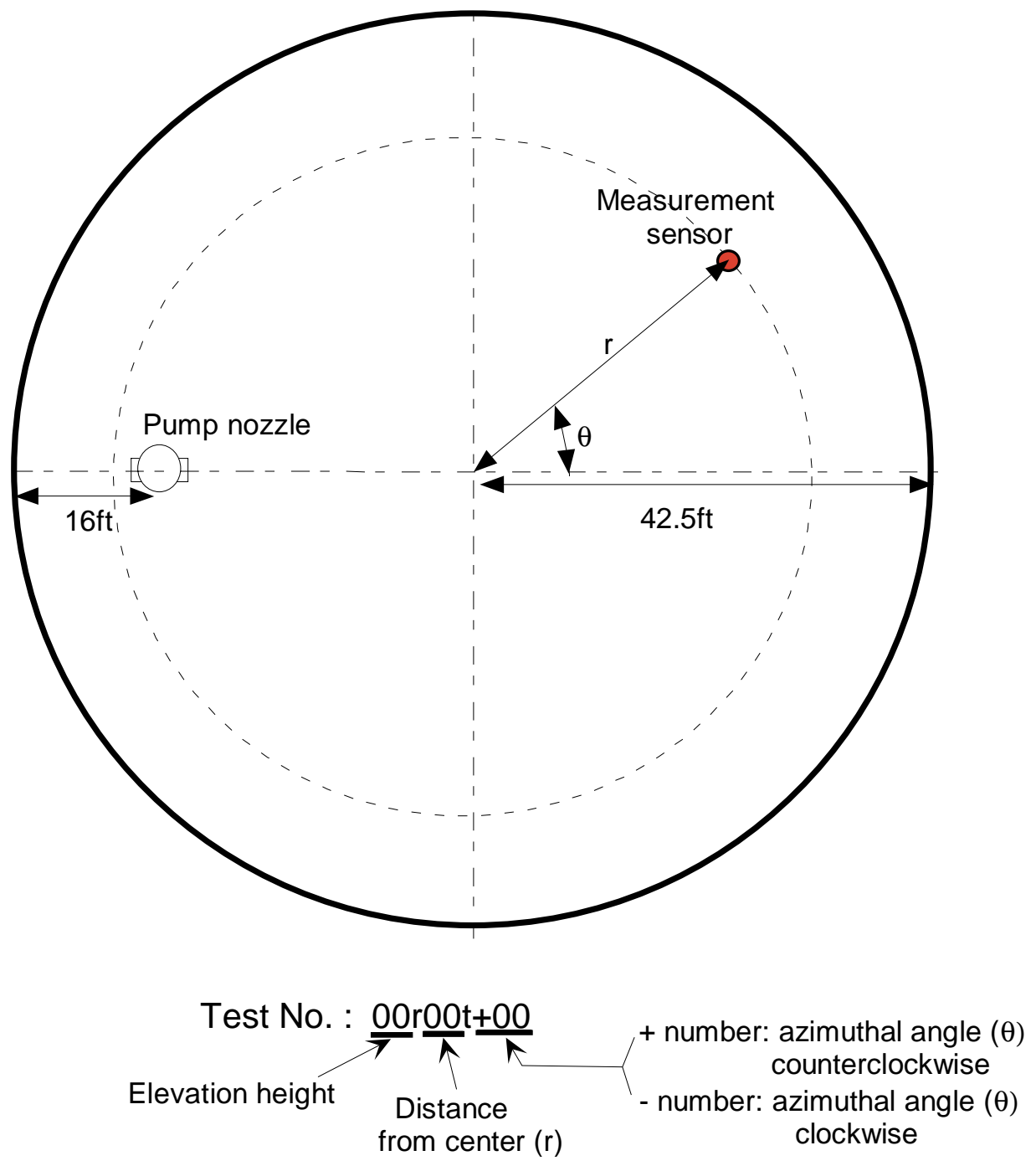

Figure A.1. Mapping of velocity measurement sensor for the TNX full tank test and notations of test number I.D. used in Table A.1. 
Report: WSRC-TR-2001-00391

Date: $\quad 04 / 05 / 02$

Page: $\quad 60$ of 66
WESTINGHOUSE SAVANNAH RIVER COMPANY

PERFORMANCE ANALYSIS FOR MIXING PUMPS OF TANK 18

Table A.1. Benchmarking results for TNX test with 3" and 27" elevations from the tank bottom

\begin{tabular}{|c|c|c|c|}
\hline Test No. & Predictions & Experiments & $\%$ error \\
\hline 03r06t-23.7 & 4.800 & 4.715 & 1.8 \\
\hline 03r06t-31.8 & 4.167 & 4.859 & -14.2 \\
\hline $03 r 12 t-18.24$ & 3.806 & 4.157 & -8.4 \\
\hline $03 r 12 t-26.34$ & 2.725 & 3.950 & -31.0 \\
\hline $03 r 18 t-18.24$ & 2.756 & 3.341 & -17.5 \\
\hline $03 r 18 t-24.58$ & 2.620 & 3.507 & -25.3 \\
\hline $03 r 24 t-15.59$ & 2.328 & 3.098 & -24.8 \\
\hline 03r24t-23.69 & 1.444 & 1.853 & -22.1 \\
\hline 03r30t-15.05 & 1.895 & 1.734 & 9.3 \\
\hline 03r30t-23.15 & 1.142 & 1.260 & -9.4 \\
\hline 03r36t-14.66 & 1.499 & 1.483 & 1.1 \\
\hline $03 r 36 t-22.76$ & 0.975 & 1.337 & -27.1 \\
\hline $03 r 42 t-14.66$ & 0.787 & 1.032 & -23.7 \\
\hline $27 \mathrm{r} 12 \mathrm{t}+5.34$ & 3.629 & 4.260 & -14.8 \\
\hline $27 \mathrm{r} 06 \mathrm{t}+10.8$ & 4.380 & 4.302 & 1.8 \\
\hline $27 \mathrm{r} 06 \mathrm{t}+15.9$ & 4.100 & 2.840 & 44.4 \\
\hline $27 \mathrm{r} 06 \mathrm{t}+16.8$ & 4.000 & 3.108 & 28.7 \\
\hline 27r06t-10.8 & 4.380 & 5.402 & -18.9 \\
\hline 27 r06t-5.34 & 4.590 & 4.623 & -0.7 \\
\hline 27r06t-23.7 & 3.644 & 3.811 & -4.4 \\
\hline 27r06t-31.8 & 3.280 & 4.085 & -19.7 \\
\hline $27 \mathrm{r} 06 \mathrm{t}+97.7$ & 0.720 & 1.858 & -61.2 \\
\hline $27 r 12 t+11.34$ & 3.270 & 2.530 & 29.3 \\
\hline $27 \mathrm{r} 12 \mathrm{t}+19.44$ & 2.526 & 2.126 & 18.8 \\
\hline $27 r 12 t-18.24$ & 3.100 & 4.033 & -23.1 \\
\hline $27 r 12 t-26.34$ & 2.210 & 3.445 & -35.8 \\
\hline $27 r 12 t-5.34$ & 3.629 & 4.036 & -10.1 \\
\hline $27 r 12 t+92.24$ & 0.100 & 1.444 & -93.1 \\
\hline $27 r 18 t-3.58$ & 3.031 & 3.137 & -3.4 \\
\hline $27 \mathrm{r} 18 \mathrm{t}-24.58$ & 1.478 & 2.642 & -44.1 \\
\hline $27 r 18 t-16.48$ & 2.223 & 3.180 & -30.1 \\
\hline $27 r 18 t+11.34$ & 2.450 & 1.745 & 40.4 \\
\hline $27 r 18 t+17.68$ & 1.911 & 1.010 & 89.2 \\
\hline
\end{tabular}


WESTINGHOUSE SAVANNAH RIVER COMPANY

PERFORMANCE ANALYSIS FOR MIXING PUMPS OF TANK 18
Report:WSRC-TR-2001-00391 Date:

$04 / 05 / 02$

Page:

61 of 66

Table A.1. Benchmarking results for TNX test with 3" and 27" elevations from the tank bottom (continued)

\begin{tabular}{|c|c|c|c|}
\hline Test No. & Predictions & Experiments & $\%$ error \\
\hline $27 r 18 t+3.58$ & 3.031 & 3.659 & -17.2 \\
\hline $27 r 24 t-2.69$ & 2.559 & 2.031 & 26.0 \\
\hline $27 r 24 t+2.69$ & 2.559 & 2.378 & 7.6 \\
\hline $27 r 24 t+16.79$ & 1.558 & 1.154 & 35.0 \\
\hline $27 r 24 t+8.69$ & 2.198 & 2.009 & 9.4 \\
\hline 27r24t-15.59 & 1.773 & 2.375 & -25.3 \\
\hline $27 r 24 t+89.59$ & 1.043 & 1.536 & -32.1 \\
\hline 27r30t-2.15 & 2.004 & 1.647 & 21.6 \\
\hline $27 r 30 t+2.15$ & 2.004 & 1.587 & 26.2 \\
\hline $27 r 30 t+8.69$ & 1.750 & 1.683 & 4.0 \\
\hline $27 r 30 t+16.25$ & 1.173 & 1.045 & 12.3 \\
\hline $27 r 30 t+89.05$ & 0.719 & 0.895 & -19.6 \\
\hline 27r30t-23.15 & 0.853 & 2.172 & -60.7 \\
\hline 27r30t-15.05 & 1.478 & 1.894 & -22.0 \\
\hline 27r36t-1.79 & 1.781 & 2.292 & -22.3 \\
\hline $27 r 36 t+1.76$ & 1.781 & 1.487 & 19.7 \\
\hline $27 r 36 t+15.86$ & 1.299 & 1.875 & -30.7 \\
\hline $27 r 36 t+7.76$ & 1.519 & 1.489 & 2.0 \\
\hline 27r36t-14.66 & 1.181 & 1.172 & 0.8 \\
\hline $27 r 36 t+88.66$ & 0.981 & 1.256 & -21.9 \\
\hline $27 r 36 t+22.76$ & 0.822 & 1.349 & -39.1 \\
\hline $27 r 42 t-1.53$ & 0.924 & 1.145 & -19.3 \\
\hline $27 r 42 t+1.53$ & 0.924 & 1.110 & -16.7 \\
\hline $27 r 42 t+7.76$ & 0.904 & 2.204 & -59.0 \\
\hline $27 r 42 t-14.43$ & 0.989 & 1.592 & -37.8 \\
\hline $27 r 42 t-22.56$ & 0.591 & 0.660 & -10.5 \\
\hline $27 r 42 t+42.63$ & 0.554 & 0.585 & -5.4 \\
\hline $27 r 42 t+69.53$ & 0.984 & 0.917 & 7.3 \\
\hline $27 r 42 t+88.43$ & 1.754 & 2.128 & -17.6 \\
\hline $27 r 42 t+7.53$ & 0.911 & 0.936 & -2.7 \\
\hline $27 r 42 t+107.53$ & 2.113 & 2.429 & -13.0 \\
\hline
\end{tabular}


Report: WSRC-TR-2001-00391

Date: $\quad 04 / 05 / 02$

Page: $\quad 62$ of 66
WESTINGHOUSE SAVANNAH RIVER COMPANY

PERFORMANCE ANALYSIS FOR MIXING PUMPS OF TANK 18

(This Page Intentionally Left Blank) 


\section{Appendix B: Quantitative Estimation of the Remaining Sludge and Zeolite Volume}

The flow patterns calculated in the Tank 18 analysis can be used to estimate the amount of sludge and zeolite that would be left behind because it is beyond the effective cleaning radius (ECR) of the pump. Observations and measurements from Tank 8 [Ref. 16] are used to quantify the ECR and calibrate the Tank 18 calculations.

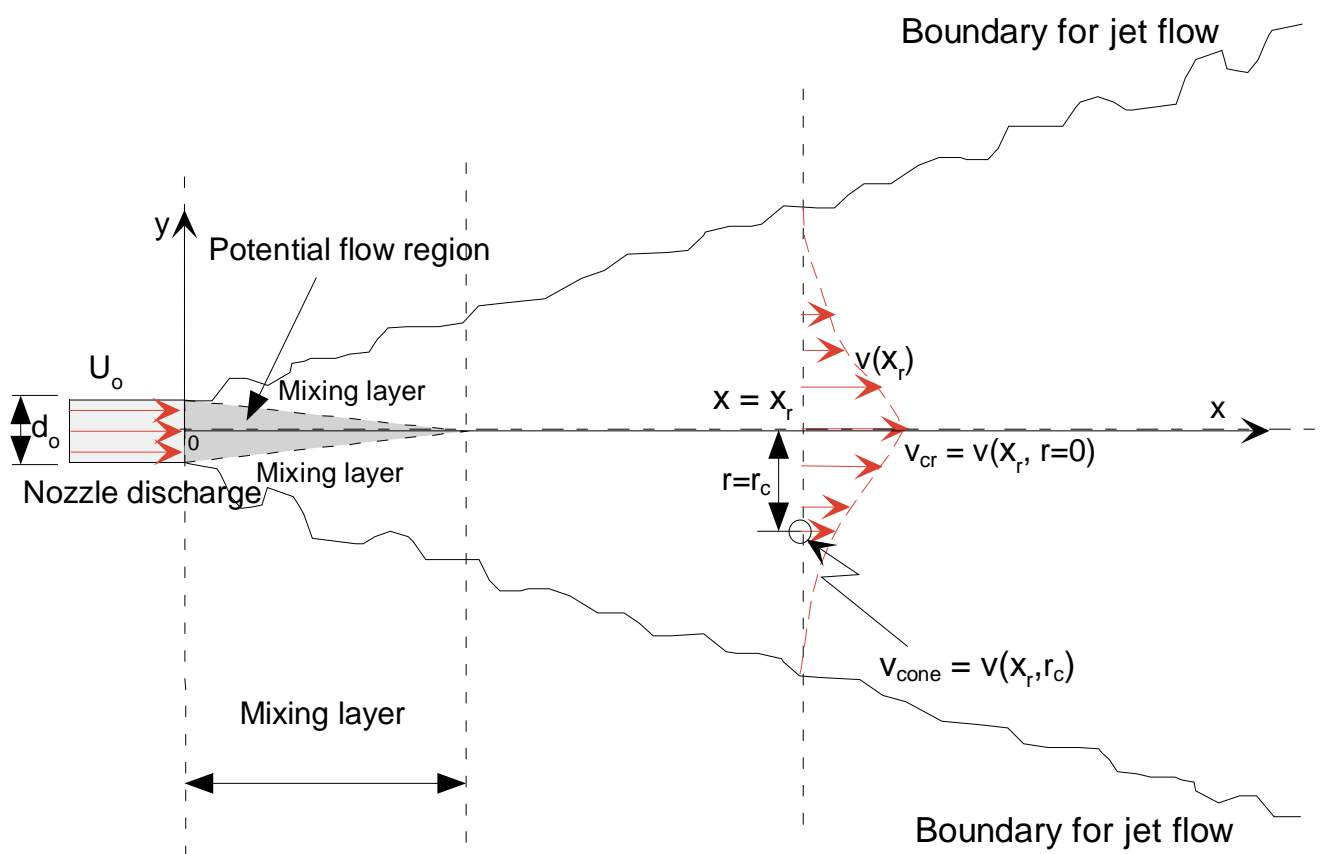

Figure B.1. Configuration of a turbulent free jet

A turbulent jet flow through a nozzle is dissipated as shown in Fig. B.1. The axial velocity distribution along the jet discharge line is described as follows:

$$
v(x, r=0)=v_{c}(x)=K\left(\frac{U_{o} d_{o}}{x}\right)
$$

Since the pump discharge flow is affected by the bottom of the tank, the constant $K$ is evaluated from the Tank 18 calculations rather than classical free jet theory. It is found to be 4.874 . The maximum axial velocity at any axial position $x$ can be estimated using eq. (B1). The radial flow distribution $v_{r}$ at a given axial position, $x=x_{r}$, is given in terms of radial position $r$ perpendicular to the jet axis by the literature [Ref. 15].

$$
\log \left(\frac{v_{c r}}{v_{r}}\right)=K_{r}\left(\frac{r}{x_{r}}\right)^{2}
$$


Page: $\quad 64$ of 66

Results from Tank 8 showed $K_{r}$ to be 9.5 [Re. 16]. Then eq. (B2) becomes

$$
\log \left(\frac{v_{c r}}{v_{\text {cone }}}\right)=9.5\left(\frac{r_{c}}{x_{r}}\right)^{2}
$$

The ECR is defined as the distance from the nozzle exit to the point along the jet axis at which the local velocity is just equal to the minimum velocity needed to suspend sludge. This velocity is identified as $v_{E C R}$. This same magnitude of velocity can be found at an off-axis location and identified with $v_{\text {cone }}$ as shown in Fig. B.1. Equating these two velocities and using eq. (B1) gives the suspension velocity,

$$
v_{E C R}=v_{\text {cone }}=K\left(\frac{U_{o} d_{o}}{E C R}\right) \text {. }
$$

From eqs. (B1) and (B4), the ratio of the axial velocity $v_{c r}$ at $x=x_{r}$ to the ECR velocity $\mathrm{V}_{\mathrm{ECR}}$ can be found.

$$
\left(\frac{v_{c r}}{v_{E C R}}\right)=\left(\frac{v_{c r}}{v_{c o n e}}\right)=\left(\frac{E C R}{x_{r}}\right) \text {. }
$$

From eqs. (B3) and (B5), the velocity terms can be eliminated. That is,

$$
\log \left(\frac{E C R}{x_{r}}\right)=9.5\left(\frac{r_{c}}{x_{r}}\right)^{2}
$$

Eq. (B6) can be used to relate two measured values from the Tank 8 report [Ref. 16], the disturbance depth $r_{c}$ and the ECR. The disturbance depth is the depth to which the sludge layer was eroded by the horizontal jet. When these values are inserted in eq. (B6), the axial location $x_{r}$ where the sludge is suspended and removed from the sludge hill can be calculated. The Tank 8 report lists the ECR and the disturbance depth $r_{c}$ as $26 \mathrm{ft}$ and $28 \mathrm{in}$, respectively, which gives a value $x_{r}=18 \mathrm{ft}$.

The sludge suspension velocity can be found from eq. (B5) if the axial velocity at $x_{r}$ is known. The axial velocity at the $18 \mathrm{ft}$ distance is given by eq. (B1). The discharge velocity at the Tank 8 jet nozzle was found to be $96.77 \mathrm{ft} / \mathrm{sec}$ for a $533 \mathrm{gpm}$ flowrate (1600 rpm) and a 1.5 in nozzle diameter. Thus, the suspension velocity of the sludge was found to be $2.27 \mathrm{ft} / \mathrm{sec}$. This value is consistent with the experimental observations in Tank 8 [Ref. 16]. Using this suspension velocity of the sludge and the present results of the Tank 18 model, the volume of the remaining sludge near the wall of the Tank 18 can be estimated. This suspension velocity for the sludge in Tank 18 corresponds to an ECR of $41.3 \mathrm{ft}$, which is about $1.2 \mathrm{ft}$ away from the tank wall.

Figures B.2 and B.3 can be used to estimate the amount of sludge and zeolite in Tank 18 that is beyond the reach of the slurry pump. An engineering estimate is that sludge material would accumulate at a slope of about $60^{\circ}$ in the bottom corner of the tank. Therefore, an ECR of $41.3 \mathrm{ft}$ would result in an accumulation as shown in Fig. B.2. If zeolite were to accumulate independently, its slope would be smaller, about $45^{\circ}$. However, it is unlikely that this independent accumulation would occur in Tank 18, and it is beyond the scope of the present analysis. The tank material is expected to be a mixture of both sludge and zeolite, so Fig. B.2 encompasses both materials. The volume of this region has been evaluated numerically and is approximately $2044 \mathrm{gal}$. 
It is possible that if the pump were to remain in a fixed position for a long enough period of time, it would ultimately erode the sludge layer and remove more sludge than is indicated in Fig. B.2. There is SRS engineering experience to indicate that this erosion could occur, but it was neither addressed nor supported by the analysis in this report.

A further question was raised about the tendency of suspended zeolite to drop out of the liquid region as the jet dispersed into the low velocity regions of the tank. While it is anticipated that such would be the case, deposition of the fast settling zeolite on the tank floor is a time dependent process that was not modeled in the present work. Qualitatively, one would expect the zeolite to drop out rather quickly once the liquid velocity dropped below that required to maintain the suspension. This would probably be in the green regions fairly close to the tank wall shown in Figure 23. That is, the deposition would be expected to follow behind the rotational motion of the jet, leaving an annular ring in approximately the outer third of the tank. The particulate would remain there until the opposing jet passed over that same region.

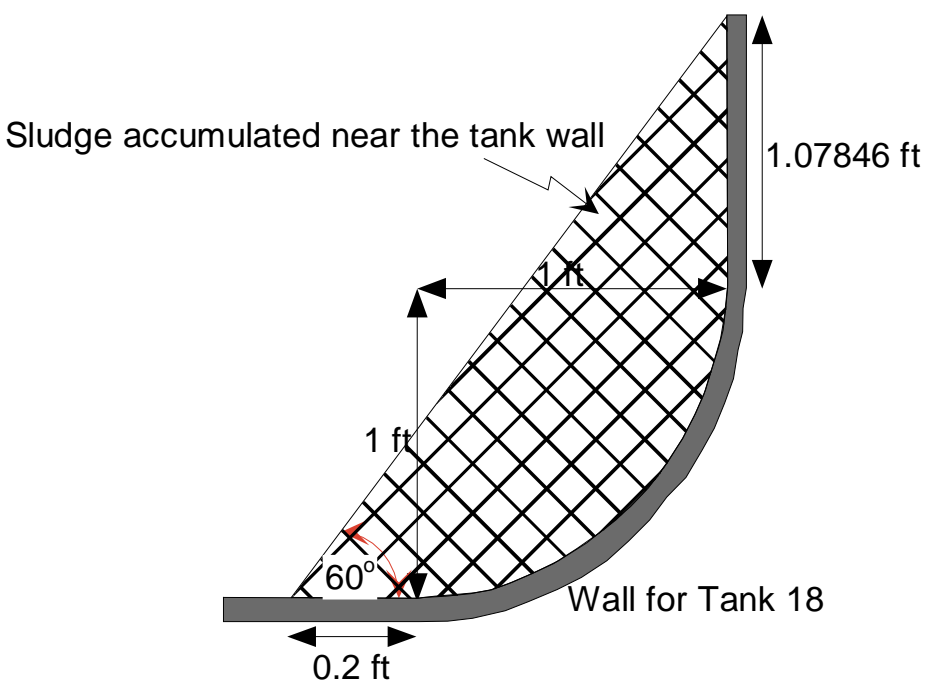

Figure B.2. Sludge mound remaining near the wall of Tank 18 
Report: WSRC-TR-2001-00391

Date: $\quad 04 / 05 / 02$

Page: $\quad 66$ of 66

\section{WESTINGHOUSE SAVANNAH RIVER COMPANY}

PERFORMANCE ANALYSIS FOR MIXING PUMPS OF TANK 18

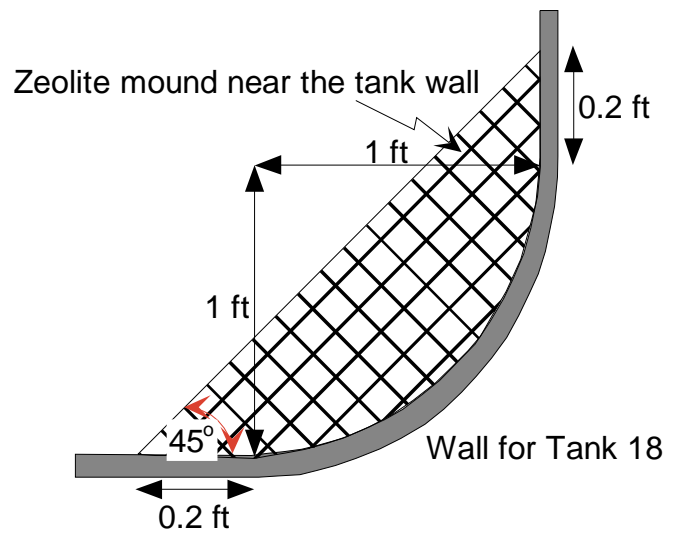

Figure B.3. Zeolite mound remaining near the wall of Tank 18 